\title{
A Review on Fatigue Life Prediction Methods for Metals
}

\author{
E. Santecchia, ${ }^{1}$ A. M. S. Hamouda, ${ }^{1}$ F. Musharavati, ${ }^{1}$ E. Zalnezhad, ${ }^{2}$ M. Cabibbo, ${ }^{3}$ \\ M. El Mehtedi, ${ }^{3}$ and S. Spigarelli ${ }^{3}$ \\ ${ }^{1}$ Mechanical and Industrial Engineering Department, College of Engineering, Qatar University, Doha 2713, Qatar
${ }^{2}$ Department of Mechanical Engineering, Hanyang University, 222 Wangsimni-ro, Seongdong-gu, Seoul 133-791, Republic of Korea
${ }^{3}$ Dipartimento di Ingegneria Industriale e Scienze Matematiche (DIISM), Università Politecnica delle Marche, 60131 Ancona, Italy
}

Correspondence should be addressed to E. Zalnezhad; erfan_zalnezhad@yahoo.com

Received 19 June 2016; Accepted 17 August 2016

Academic Editor: Philip Eisenlohr

Copyright (C) 2016 E. Santecchia et al. This is an open access article distributed under the Creative Commons Attribution License, which permits unrestricted use, distribution, and reproduction in any medium, provided the original work is properly cited.

\begin{abstract}
Metallic materials are extensively used in engineering structures and fatigue failure is one of the most common failure modes of metal structures. Fatigue phenomena occur when a material is subjected to fluctuating stresses and strains, which lead to failure due to damage accumulation. Different methods, including the Palmgren-Miner linear damage rule- (LDR-) based, multiaxial and variable amplitude loading, stochastic-based, energy-based, and continuum damage mechanics methods, forecast fatigue life. This paper reviews fatigue life prediction techniques for metallic materials. An ideal fatigue life prediction model should include the main features of those already established methods, and its implementation in simulation systems could help engineers and scientists in different applications. In conclusion, LDR-based, multiaxial and variable amplitude loading, stochastic-based, continuum damage mechanics, and energy-based methods are easy, realistic, microstructure dependent, well timed, and damage connected, respectively, for the ideal prediction model.
\end{abstract}

\section{Introduction}

Avoiding or rather delaying the failure of any component subjected to cyclic loadings is a crucial issue that must be addressed during preliminary design. In order to have a full picture of the situation, further attention must be given also to processing parameters, given the strong influence that they have on the microstructure of the cast materials and, therefore, on their properties.

Fatigue damage is among the major issues in engineering, because it increases with the number of applied loading cycles in a cumulative manner, and can lead to fracture and failure of the considered part. Therefore, the prediction of fatigue life has an outstanding importance that must be considered during the design step of a mechanical component [1].

The fatigue life prediction methods can be divided into two main groups, according to the particular approach used. The first group is made up of models based on the prediction of crack nucleation, using a combination of damage evolution rule and criteria based on stress/strain of components. The key point of this approach is the lack of dependence from loading and specimen geometry, being the fatigue life determined only by a stress/strain criterion [2].

The approach of the second group is based instead on continuum damage mechanics (CDM), in which fatigue life is predicted computing a damage parameter cycle by cycle [3]

Generally, the life prediction of elements subjected to fatigue is based on the "safe-life" approach [4], coupled with the rules of linear cumulative damage (Palmgren [5] and Miner [2]). Indeed, the so-called Palmgren-Miner linear damage rule (LDR) is widely applied owing to its intrinsic simplicity, but it also has some major drawbacks that need to be considered [6]. Moreover, some metallic materials exhibit highly nonlinear fatigue damage evolution, which is load dependent and is totally neglected by the linear damage rule [7]. The major assumption of the Miner rule is to consider the fatigue limit as a material constant, while a number of studies showed its load amplitude-sequence dependence [8-10].

Various other theories and models have been developed in order to predict the fatigue life of loaded structures [11-24]. 
Among all the available techniques, periodic in situ measurements have been proposed, in order to calculate the macrocrack initiation probability [25].

The limitations of fracture mechanics motivated the development of local approaches based on continuum damage mechanics (CDM) for micromechanics models [26]. The advantages of CDM lie in the effects that the presence of microstructural defects (voids, discontinuities, and inhomogeneities) has on key quantities that can be observed and measured at the macroscopic level (i.e., Poisson's ratio and stiffness). From a life prediction point of view, CDM is particularly useful in order to model the accumulation of damage in a material prior to the formation of a detectable defect (e.g., a crack) [27]. The CDM approach has been further developed by Lemaitre [28, 29]. Later on, the thermodynamics of irreversible process provided the necessary scientific basis to justify CDM as a theory [30] and, in the framework of internal variable theory of thermodynamics, Chandrakanth and Pandey [31] developed an isotropic ductile plastic damage model. De Jesus et al. [32] formulated a fatigue model involving a CDM approach based on an explicit definition of fatigue damage, while Xiao et al. [33] predicted high-cycle fatigue life implementing a thermodynamics-based CDM model.

Bhattacharya and Ellingwood [26] predicted the crack initiation life for strain-controlled fatigue loading, using a thermodynamics-based CDM model where the equations of damage growth were expressed in terms of the Helmholtz free energy.

Based on the characteristics of the fatigue damage, some nonlinear damage cumulative theories, continuum damage mechanics approaches, and energy-based damage methods have been proposed and developed [11-14, 21-23, 34, 35].

Given the strict connection between the hysteresis energy and the fatigue behavior of materials, expressed firstly by Inglis [36], energy methods were developed for fatigue life prediction using strain energy (plastic energy, elastic energy, or the summation of both) as the key damage parameter, accounting for load sequence and cumulative damage $[18,37-$ 45].

Lately, using statistical methods, Makkonen [19] proposed a new way to build design curves, in order to study the crack initiation and to get a fatigue life estimation for any material.

A very interesting fatigue life prediction approach based on fracture mechanics methods has been proposed by Ghidini and Dalle Donne [46]. In this work they demonstrated that, using widespread aerospace fracture mechanics-based packages, it is possible to get a good prediction on the fatigue life of pristine, precorroded base, and friction stir welded specimens, even under variable amplitude loads and residual stresses conditions [46].

In the present review paper, various prediction methods developed so far are discussed. Particular emphasis will be given to the prediction of the crack initiation and growth stages, having a key role in the overall fatigue life prediction. The theories of damage accumulation and continuum damage mechanics are explained and the prediction methods based on these two approaches are discussed in detail.

\section{Prediction Methods}

According to Makkonen [19], the total fatigue life of a component can be divided into three phases: (i) crack initiation, (ii) stable crack growth, and (iii) unstable crack growth. Crack initiation accounts for approximately 40-90\% of the total fatigue life, being the phase with the longest time duration [19]. Crack initiation may stop at barriers (e.g., grain boundaries) for a long time; sometimes the cracks stop completely at this level and they never reach the critical size leading to the stable growth.

A power law formulated by Paris and Erdogan [47] is commonly used to model the stable fatigue crack growth:

$$
\frac{d a}{d N}=C \cdot \Delta K^{m}
$$

and the fatigue life $N$ is obtained from the following integration:

$$
N=\int_{a_{i}}^{a_{f}} \frac{d a}{C \cdot(\Delta K)^{m}},
$$

where $\Delta K$ is the stress intensity factor range, while $C$ and $m$ are material-related constants. The integration limits $a_{i}$ and $a_{f}$ correspond to the initial and final fatigue crack lengths.

According to the elastic-plastic fracture mechanics (EPFM) [48-50], the crack propagation theory can be expressed as

$$
\frac{d a}{d N}=C^{\prime} \Delta J^{m^{\prime}}
$$

where $\Delta J$ is the $J$ integral range corresponding to (1), while $C^{\prime}$ and $m^{\prime}$ are constants.

A generalization of the Paris law has been recently proposed by Pugno et al. [51], where an instantaneous crack propagation rate is obtained by an interpolating procedure, which works on the integrated form of the crack propagation law (in terms of $S-N$ curve), in the imposed condition of consistency with Wöhler's law [52] for uncracked material $[51,53]$.

2.1. Prediction of Fatigue Crack Initiation. Fatigue cracks have been a matter of research for a long time [54]. Hachim et al. [55] addressed the maintenance planning issue for a steel S355 structure, predicting the number of priming cycles of a fatigue crack. The probabilistic analysis of failure showed that the priming stage, or rather the crack initiation stage, accounts for more than $90 \%$ of piece life. Moreover, the results showed that the propagation phase could be neglected when a large number of testing cycles are performed [55].

Tanaka and Mura [56] were pioneers concerning the study of fatigue crack initiation in ductile materials, using the concept of slip plastic flow. The crack starts to form when the surface energy and the stored energy (given by the dislocations accumulations) become equal, thus turning the dislocation dipoles layers into a free surface $[56,57]$.

In an additional paper [58], the same authors modeled the fatigue crack initiation by classifying cracks at first as 
(i) crack initiation from inclusions (type A), (ii) inclusion cracking by impinging slip bands (type B), and (iii) slip band crack emanating from an uncracked inclusion (type C). The type A crack initiation from a completely debonded inclusion was treated like crack initiation from a void (notch). The initiation of type B cracks at the matrix-particle interface is due to the impingement of slip bands on the particles, but only on those having a smaller size compared to the slip band width. This effect inhibits the dislocations movements. The fatigue crack is generated when the dislocation dipoles get to a level of self-strain energy corresponding to a critical value. For crack initiation along a slip band, the dislocation dipole accumulation can be described as follows:

$$
(\Delta \tau-2 k) N_{1}^{1 / 2}=\left[\frac{8 \mu W_{s}}{\pi d}\right]^{1 / 2},
$$

where $W_{s}$ is the specific fracture energy per unit area along the slip band, $k$ is the friction stress of dislocation, $\mu$ is the shear modulus, $\Delta \tau$ is the shear stress range, and $d$ is the grain size [58]. Type $\mathrm{C}$ was approximated by the problem of dislocation pile-up under the stress distribution in a homogeneous, infinite plane. Type A mechanism was reported in high strength steels, while the other two were observed in high strength aluminum alloys. The quantitative relations derived by Tanaka and Mura [58] correlated the properties of matrices and inclusions, as well as the size of the latter, with the fatigue strength decrease at a given crack initiation life and with the reduction of the crack initiation life at a given constant range of the applied stress [58].

Dang-Van [59] also considered the local plastic flow as essential for the crack initiation, and he attempted to give a new approach in order to quantify the fatigue crack initiation [59].

Mura and Nakasone [60] expanded Dang-Van's work to calculate the Gibbs free energy change for fatigue crack nucleation from piled up dislocation dipoles.

Assuming that only a fraction of all the dislocations in the slip band contributes to the crack initiation, Chan [61] proposed a further evolution of this theory.

Considering the criterion of minimum strain energy accumulation within slip bands, Venkataraman et al. [6264] generalized the dislocation dipole model and developed a stress-initiation life relation predicting a grain-size dependence, which was in contrast with the Tanaka and Mura theory $[56,58]$ :

$$
(\Delta \tau-2 k)_{i}^{\alpha}=0.37\left(\frac{\mu d}{e h}\right)\left(\frac{\gamma_{s}}{\mu d}\right)^{1 / 2}
$$

where $\gamma_{s}$ is the surface-energy term and $e$ is the slipirreversibility factor $(0<e<1)$. This highlighted the need to incorporate key parameters like crack and microstructural sizes, to get more accurate microstructure-based fatigue crack initiation models [61].

Other microstructure-based fatigue crack growth models were developed and verified by Chan and coworkers [61, 6567].

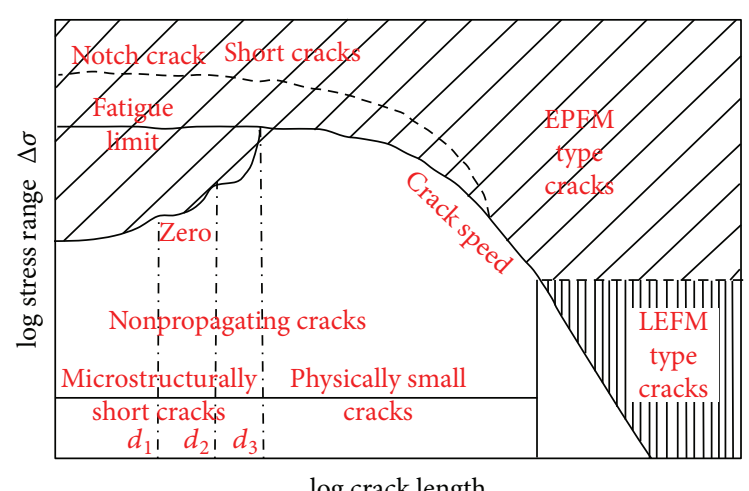

Figure 1: A modified Kitagawa-Takahashi $\Delta \sigma-a$ diagram, showing boundaries between MSCs and PSCs and between EPFM cracks and LEFM cracks $[69,71]$.

Concerning the metal fatigue, after the investigation of very-short cracks behavior, Miller and coworkers proposed the immediate crack initiation model [68-71]. The early two phases of the crack follow the elastoplastic fracture mechanics (EPFM) and were renamed as (i) microstructurally short crack (MSC) growth and (ii) physically small crack (PSC) growth. Figure 1 shows the modified Kitagawa-Takahashi diagram, highlighting the phase boundaries between MSC and PSC $[69,71]$.

The crack dimension has been identified as a crucial factor by a number of authors, because short fatigue cracks (having a small length compared to the scale of local plasticity, or to the key microstructural dimension, or simply smaller than $1-2 \mathrm{~mm}$ ) in metals grow at faster rate and lower nominal stress compared to large cracks $[72,73]$.

2.1.1. Acoustic Second Harmonic Generation. Kulkarni et al. [25] proposed a probabilistic method to predict the macrocrack initiation due to fatigue damage. Using acoustic nonlinearity, the damage prior to macrocrack initiation was quantified, and the data collected were then used to perform a probabilistic analysis. The probabilistic fatigue damage analysis results from the combination of a suitable damage evolution equation and a procedure to calculate the probability of a macrocrack initiation, the Monte Carlo method in this particular case. Indeed, when transmitting a single frequency wave through the specimen, the distortion given by the material nonlinearity generates second higher level harmonics, having amplitudes increasing with the material nonlinearity. As a result, both the accumulated damage and material nonlinearity can be characterized by the ratio $A_{2} / A_{1}$, where $A_{2}$ is the amplitude of the second harmonic and $A_{1}$ is the amplitude of the fundamental one. The ratio is expected to increase with the progress of the damage accumulation. It is important to point out that this $A_{2} / A_{1}$ acoustic nonlinearity characterization [74] differs from the approach given by Morris et al. [75].

In the work of Ogi et al. [74] two different signals were transmitted separately into a specimen, one at resonance frequency $f_{r}$ and the other at half of this frequency $\left(f_{r} / 2\right)$. 


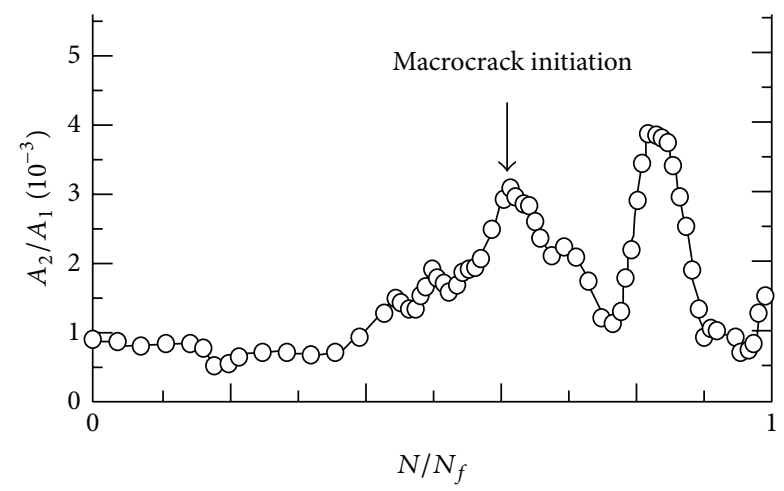

FIgURE 2: Typical evolution of the ratio $A_{2}\left(f_{r} / 2\right) / A_{1}\left(f_{r}\right)$ for 0.25 mass\% C steel, $N_{f}=56,000[74]$.

The transmission of a signal at $f_{r}$ frequency generates a measured amplitude $A_{1}\left(f_{r}\right)$, and while the signal is transmitted at frequency $f_{r} / 2$, the amplitude $A_{2}\left(f_{r} / 2\right)$ was received. The measurement of both signals ensures the higher accuracy of this method [74]. Figure 2 shows that the $A_{2}\left(f_{r} / 2\right) / A_{1}\left(f_{r}\right)$ ratio increases nearly monotonically, and at the point of the macrocrack initiation a distinct peak can be observed. This result suggests that the state of damage in a specimen during fatigue tests can be tracked by measuring the ratio $A_{2} / A_{1}$.

According to the model of Ogi et al. [74], Kulkarni et al. [25] showed that the scalar damage function can be written as $D(N)$, designating the damage state in a sample at a particular fatigue cycle. The value $D=0$ corresponds to the no-damage situation, while $D=1$ denotes the appearance of the first macrocrack. The damage evolution with the number of cycles is given by the following equation:

$$
\frac{d D}{d N}=\frac{1}{N_{c}}\left(\frac{\Delta \sigma / 2-r_{c}(\bar{\sigma})}{\Delta \sigma / 2}\right)^{m} \frac{1}{(1-D)^{n}}
$$

When $\Delta \sigma / 2$ is higher than the endurance limit $\left(r_{c}(\bar{\sigma})\right)$, otherwise the rate $d D / d N$ equals zero.

2.1.2. Probability of Crack Initiation on Defects. Melander and Larsson [76] used the Poisson statistics to calculate the probability $P_{x}$ of a fatigue life smaller than $x$ cycles. Excluding the probability of fatigue crack nucleation at inclusions, $P_{x}$ can be written as

$$
P_{x}=1-\exp \left(-\lambda_{x}\right)
$$

where $\lambda_{x}$ is the number of inclusions per unit volume. Therefore, (7) shows the probability to find at least one inclusion in a unity volume that would lead to fatigue life not higher than $x$ cycles.

In order to calculate the probability of fatigue failure $P$, de Bussac and Lautridou [77] used a similar approach. In their model, given a defect of size $D$ located in a volume adjacent to the surface, the probability of fatigue crack initiation was assumed to be equal to that of encountering a discontinuity with the same dimension:

$$
P=1-\exp \left(-N_{v} D\right)
$$

with $N_{v}$ as the number of defects per unit volume having diameter $D$. As in the model developed by Melander and Larsson [76], also in this case an equal crack initiation power for different defects having the same size is assumed $[77,78]$.

In order to account for the fact that the fatigue crack initiation can occur at the surface and inside a material, de Bussac [79] defined the probability to find discontinuities of a given size at the surface or at the subsurface. Given a number of load cycles $N_{0}$, the survival probability $P$ is determined as the product of the survival probabilities of surface and subsurface failures:

$$
P=\left[1-p_{s}\left(D_{s}\right)\right]\left[1-p_{v}\left(D_{v}\right)\right],
$$

where $D_{s}$ and $D_{v}$ are the diameters of the discontinuities in surface and subsurface leading to $N_{0}$ loads life. $p_{s}\left(D_{s}\right)$ and $p_{v}\left(D_{v}\right)$ are the probabilities of finding a defect larger than $D_{s}$ and $D_{v}$ at surface and subsurface, respectively. It must be stressed that this model does not rely on the type of discontinuity but only on its size [79].

Manonukul and Dunne [80] studied the fatigue crack initiation in polycrystalline metals addressing the peculiarities of high-cycle fatigue (HCF) and low-cycle fatigue (LCF). The proposed approach for the prediction of fatigue cracks initiation is based on the critical accumulated slip property of a material; the key idea is that when the critical slip is achieved within the microstructure, crack initiation should have occurred. The authors developed a finite-element model for the nickel-based alloy C263 where, using crystal plasticity, a representative region of the material (containing about 60 grains) was modeled, taking into account only two materials properties: (i) grain morphology and (ii) crystallographic orientation.

The influence on the fatigue life due to the initial conditions of the specimens was studied deeply by Makkonen $[81,82]$, who addressed in particular the size of the specimens and the notch size effects, both in the case of steel as testing material.

The probability of crack initiation and propagation from an inclusion depends on its size and shape as well as on the specimen size, because it is easier to find a large inclusion in a big component rather than in a small specimen $[77,79,83-$ 85].

2.2. Fatigue Crack Growth Modeling. The growth of a crack is the major manifestation of damage and is a complex phenomenon involving several processes such as (i) dislocation agglomeration, (ii) subcell formation, and (iii) multiple microcracks formation (independently growing up to their connection) and subsequent dominant crack formation [39].

The dimensions of cracks are crucial for modeling their growth. An engineering analysis is possible considering the relationships between the crack growth rates associated with the stress intensity factor, accounting for the stress conditions 
at the crack tip. Of particular interest is the behavior and modeling of small and short cracks $[4,86]$, in order to determine the conditions leading to cracks growth up to a level at which the linear elastic fracture mechanics (LEFM) theory becomes relevant. Fatigue cracks can be classified as short if one of their dimensions is large compared to the microstructure, while the small cracks have all dimensions similar or smaller than those of the largest microstructural feature [87].

Tanaka and Matsuoka studied the crack growth in a number of steels and determined a proper best-fit relation for room temperature growth conditions $[88,89]$.

2.2.1. Deterministic Crack Growth Models. While the ParisErdogan [48] model is valid only in the macrocrack range, a deterministic fatigue crack model can be obtained starting from the short crack growth model presented by Newman Jr. [93]. Considering $N$ cycles and a medium crack length $\mu$, the crack growth rate can be calculated as follows:

$$
\frac{d \mu}{d N}=\exp \left[m \ln \left(\Delta K_{\mathrm{eff}}\right)+b\right] ; \quad \mu\left(N_{0}\right)=\mu_{0}>0,
$$

where $\Delta K_{\text {eff }}$ is the linear elastic effective stress intensity factor range and $m$ and $b$ are the slope and the intercept of the linear interpolation of the (log scale) $\Delta K_{\text {eff }}-d \mu / d N$, respectively. In order to determine the crack growth rate, Spencer Jr. et al. [94, 95] used the cubic polynomial fit in $\ln \left(\Delta K_{\text {eff }}\right)$. Therefore, the crack growth rate equation can be written in the continuoustime setting as follows $[96,97]$ :

$$
\frac{d \mu}{d t}=\frac{(\partial \Phi / \partial S) \cdot(d S / d t)}{(1-\partial \Phi) / \partial \mu} ; \quad \mu_{0}\left(t_{0}\right)=\mu_{0}>0
$$

Manson and Halford [98] introduced an effective crack growth model accounting for the processes taking place meanwhile, using

$$
a=a_{0}+\left(a_{f}-a_{0}\right) r^{q}
$$

where $a_{0}, a$, and $a_{f}$ are initial ( $\left.r=0\right)$, instantaneous, and final $(r=1)$ cracks lengths, respectively, while $q$ is a function of $N$ in the form $q=B N^{\beta}$ ( $B$ and $\beta$ are material's constants).

A fracture mechanics-based analysis addressing bridges and other steel structures details has been made by Righiniotis and Chryssanthopoulos [99], accounting for the acceptability of flaws in fusion welded structures [100].

2.2.2. Stochastic Crack Growth Models. The growth of a fatigue crack can be also modeled by nonlinear stochastic equations satisfying the Itô conditions [94-101]. Given that $E\left[c\left(\omega, t_{0}\right)\right]=\mu_{0}$ and $\operatorname{cov}\left[c\left(\omega, t_{0}\right)\right]=P_{0}$, the stochastic differential equation for the crack growth process $c(\omega, t)$ can be written according to the deterministic damage dynamics as

$$
\frac{d c(\omega, t)}{d t}=\exp \left[z(\omega, t)-\frac{\sigma_{z}^{2}(t)}{2}\right] \cdot \frac{d \mu}{d t} \quad \forall t \geq t_{0}
$$

If $\omega$ and $t$ represent the point and time of the sample in the stochastic process, the auxiliary process $z(\omega, t)$ is assumed to be a stationary Gauss-Markov one having variance $\sigma_{z}^{2}(t)$, which implies the rational condition of a lognormal-distributed crack growth [96].

In order to clarify the influence of the fracture peculiarities on the failure probability of a fatigue loaded structure, Maljaars et al. [102] used the linear elastic fracture mechanics (LEFM) theory to develop a probabilistic model.

Ishikawa et al. [103] proposed the Tsurui-Ishikawa model, while Yazdani and Albrecht [104] investigated the application of probabilistic LEFM to the prediction of the inspection interval of cover plates in highway bridges. As for the welded structures, a comprehensive overview of probabilistic fatigue assessment models can be found in the paper of Lukić and Cremona [105]. In this study, the effect of almost all relevant random variables on the failure probability is treated [105].

The key feature of the work of Maljaars et al. [102] with respect to other LEFM-based fatigue assessment studies [87, 103-105] is that it accounts for the fact that, at any moment in time, a large stress cycle causing fracture can occur. Therefore, the probability of failure in case of fatigue loaded structures can be calculated combining all the failure probabilities for all time intervals.

Considering the stress ranges as randomly distributed, the expectation of $d a / d N$ can be written as a function of the expectation of the stress range $\Delta \sigma$, as follows (see (14)):

$$
\begin{gathered}
E\left(\frac{d a}{d N}\right) \\
=A_{1} E\left[\Delta \sigma^{m_{1}}\right]_{\Delta \sigma_{\mathrm{th}}}^{\Delta \sigma_{\mathrm{tr}}} \\
\cdot\left(\left[\frac{B_{\mathrm{nom}}}{B}\right]^{P} C_{\mathrm{load}} C_{\mathrm{glob}} C_{\mathrm{scf}} C_{\text {sif }} Y_{a} \sqrt{\pi a}\right)^{m_{1}} \ldots \\
+A_{2} E\left[\Delta \sigma^{m_{2}}\right]_{\Delta \sigma_{\mathrm{tr}}}^{\infty} \\
\cdot\left(\left[\frac{B_{\mathrm{nom}}}{B}\right]^{p} C_{\mathrm{load}} C_{\mathrm{glob}} C_{\mathrm{scf}} C_{\text {sif }} Y_{a} \sqrt{\pi a}\right)^{m_{2}}, \\
E\left[\Delta \sigma^{m}\right]_{s_{1}}^{s_{2}}=\int_{s_{1}}^{s_{2}} s^{m} f_{\Delta \sigma}(s) d s,
\end{gathered}
$$

where $f_{\Delta \sigma}(s)$ is the probability density function of the stress ranges $\Delta \sigma$ and $s$ represents the stress range steps. The $C$ factors are the uncertainties of the fluctuating load mode. In (14) $B_{\text {nom }}$ represents the plate thickness (considering a welded plate) used in the calculation of the stress, while $P$ is the thickness exponent. The probabilistic LEFM model applied on fatigue loaded structures typical of civil enegineering showed that modeling the uncertainity factors is the key during the assessment of the failure probability, which is quite independent of the particular failure criterion. The partial factors introduced to meet the reliability requirements of civil engineering structures and derived for various values of the reliability index $(\beta)$ appeared to be insensitive to other parameters such as load spectrum and geometry [102]. 
2.3. Stochastic Methods for Fatigue Life Prediction. Ting and Lawrence [106] showed that, for an Al-Si alloy, there was a remarkable difference between the size distributions of the casting pores and of those that initiated dominant fatigue cracks.

In order to consider also the size of the defects, Todinov [78] classified them into categories according to their size and then divided them into groups, according to the probability of fatigue crack initiation. Other than type and size, an additional separation was done, when needed, based on the shape of the defects. Considering $M-1$ groups (where $M$ is the index reserved for the matrix), having a $p_{i}$ average probability of fatigue crack initiation each, it is possible to calculate the probability $P_{i}$ that at least one fatigue crack initiated in the $i$ th group as

$$
P_{i}=1-\left(1-p_{i}\right)^{N_{i}}
$$

where $\left(1-p_{i}\right)^{N_{i}}$ is the probability that none of the group's defects initiated a fatigue crack, while $N_{i}$ represents the number of discontinuities in the group. The fatigue crack is supposed to be generated on the $j$ th defect of the $i$ th group $\left(j=1, N_{i}\right)$. The probability $P_{i}$ is not affected by the presence of other groups of defects, because they do not affect the fatigue stress range.

Figure 3 shows that, given a circle having unit area and corresponding to the matrix, the area of the overlapping domains located in this circle is numerically equal to the total probabilities $P_{i}$. The $i$ index domain overlaps with greater index domains, thus resulting in the following relations between the average fatigue lives of the groups: $L_{i} \leq L_{i+1} \leq$ $\cdots \leq L_{M}$ [78]. $f_{i}$ is the frequency of failure or rather the probability that, in the $i$ th group of defects, a dominant fatigue crack initiates. The shortest fatigue life is given by the cracks generated in the first group (all dominant) and therefore $f_{1}=P_{1}$. Recurrent equations can be used to express the dependence between the probabilities and the fatigue failure frequencies:

$$
\begin{aligned}
f_{1} & =P_{1}, \\
f_{2} & =P_{2}\left(1-P_{1}\right) \\
f_{3} & =P_{3}\left(1-P_{1}\right)\left(1-P_{2}\right) \\
f_{M} & =P_{M}\left(1-P_{1}\right)\left(1-P_{2}\right) \cdots\left(1-P_{M-1}\right) .
\end{aligned}
$$

This can be reduced to

$$
P_{i}=\frac{f_{i}}{1-\sum_{j-1}^{i-1} f_{j}}=\frac{f_{i}}{\sum_{j=i}^{M} f_{j}}, \quad i=1, M .
$$

Considering a new distribution $N_{i}^{\prime}$ of defects in the groups, the probabilities $P_{i}^{\prime}$ are calculated according to (16), while failure frequencies are calculated as follows:

$$
f_{i}^{\prime}=P_{i}^{\prime}\left(1-\sum_{j=1}^{i-1} f_{j}^{\prime}\right), \quad i=2, M .
$$

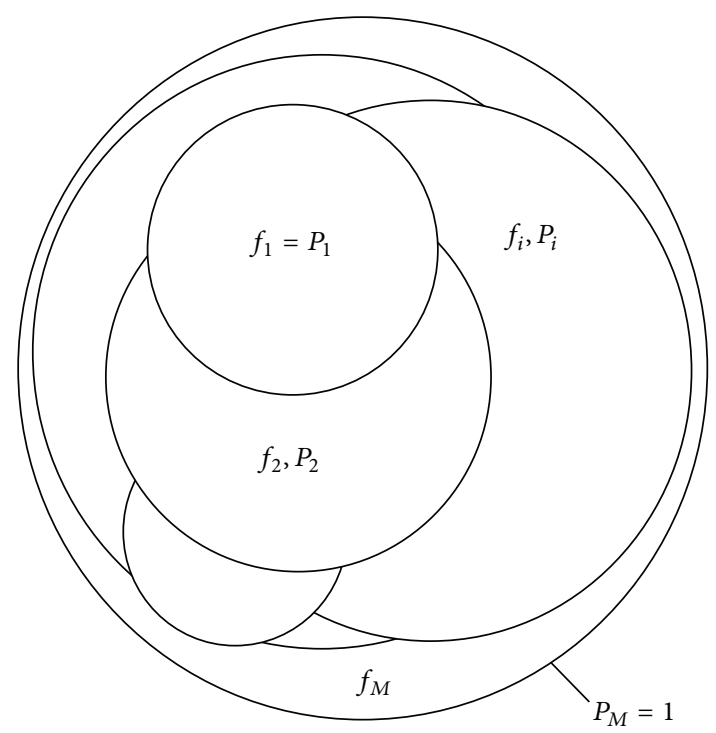

FIGURE 3: Probabilities that at least one fatigue crack had been nucleated in the $i$ th group of defects $\left(P_{M}\right.$ is the probability for nucleation in the matrix). Fatigue failure frequencies $f_{i}$ (the probability for initiation of a dominant fatigue crack in the ith group) are numerically equal to the area of the nonoverlapped regions (adapted from [78]).

With the new failure frequencies being $f_{i}^{\prime}(i=1, M)$ and the average fatigue lives being $L_{i}, i=1, M$, the expected fatigue life $\bar{L}$ can be determined as follows [78]:

$$
\begin{aligned}
\bar{L}= & \sum_{i=1}^{M} f_{i}^{\prime} L_{i} \\
= & P_{1}^{\prime} L_{1}+P_{2}^{\prime}\left(1-P_{1}^{\prime}\right) L_{2}+\cdots \\
& +P_{M}^{\prime}\left(1-P_{1}^{\prime}\right)\left(1-P_{2}^{\prime}\right) \cdots\left(1-P_{M-1}^{\prime}\right) L_{M} .
\end{aligned}
$$

The Monte-Carlo simulation showed that, in the case of cast aluminum alloys, the fatigue life depends more on the type and size of the defects where the fatigue crack arises than on other parameters concerning the fatigue crack initiation and propagation. In general, it can be stated that the probability of fatigue crack initiation from discontinuities and the variation of their sizes produce a large scatter in the fatigue life [78].

A nonlinear stochastic model for the real-time computations of the fatigue crack dynamics has been developed by Ray and Tangirala [96].

Ray [107] presented a stochastic approach to model the fatigue crack damage of metallic materials. The probability distribution function was generated in a close form without solving the differential equations; this allowed building algorithms for real-time fatigue life predictions [107].

Many static failure criteria such as Shokrieh and Lessard, Tsay-Hill, Tsai-Wu, and Hashin can be converted into fatigue failure criterion, by replacing the static strength with fatigue strength in the failure criterion [108-111]. 


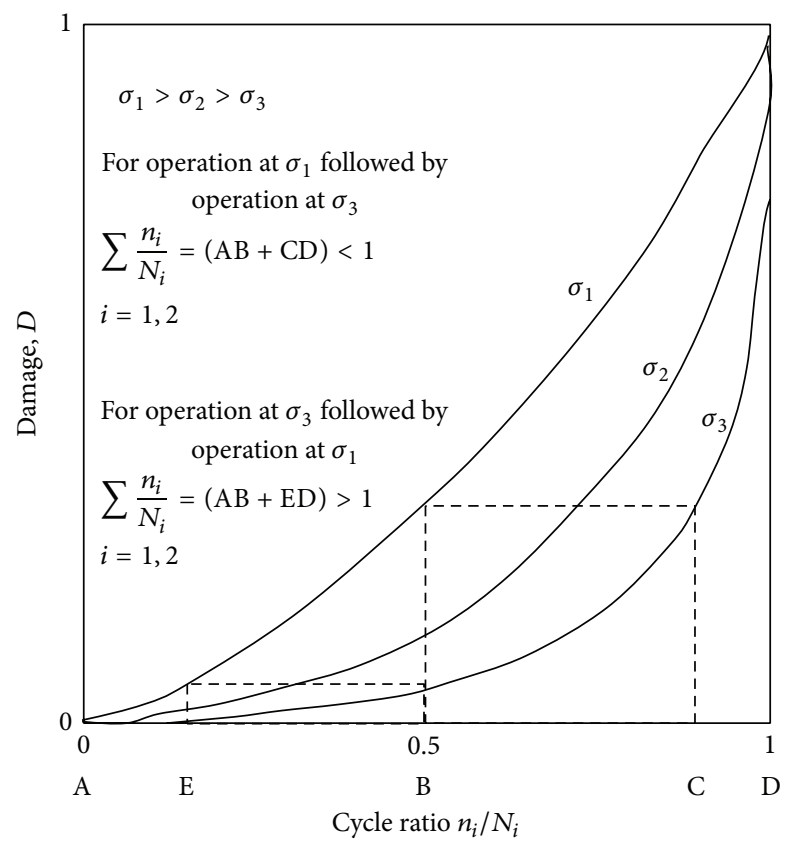

FIGURE 4: A schematic representation for the Marco-Starkey theory [90].

2.4. Cumulative Damage Models for Fatigue Lifetime Calculation. The most popular cumulative damage model for fatigue life prediction is based on the Palmer intuition [5] of a linear accumulation. Miner [2] was the first researcher who wrote the mathematical form of this theory. The Palmgren-Miner rule, also known as linear damage accumulation rule (LDR), stated that at the failure the value of the fatigue damage $D$ reaches the unity [2]:

$$
D=\sum \frac{n_{i}}{N_{i}}=1
$$

The LDR theory is widely used owing to its intrinsic simplicity, but it leans on some basic assumptions that strongly affect its accuracy such as (i) the characteristic amount of work absorbed at the failure and (ii) the constant work absorbed per cycle [39]. From the load sequence point of view, the lack of consideration leads to experimental results that are lower than those obtained by applying the Miner rule under the same loading conditions for high-to-low load sequence and higher results for the opposite sequence.

In order to overcome the LDR shortcomings, firstly Richart and Newmark [112] proposed the damage curve, correlating the damage and the cycle ratio $\left(D-n_{i} / N_{i}\right.$ diagram). Based on this curve and with the purpose of further improving the LDR theory accuracy, the first nonlinear load dependent damage accumulation theory was suggested by Marco and Starkey [90]:

$$
D=\sum\left(\frac{n_{i}}{N_{i}}\right)^{C_{i}} .
$$

The Palmgren-Miner rule is a particular case of the MarcoStarkey theory where $C_{i}=1$, as reported in Figure 4 .
The effect of the load sequence is highlighted in Figure 4, since for low-to-high loads $\sum\left(n_{i} / N_{i}\right)>1$, while for the highto-low sequence the summation is lower than the unity [90].

Other interesting theories accounting for load interaction effects can be found in literature [113-122].

The two-stage linear damage theory $[123,124]$ was formulated in order to account for two types of damage due to (i) crack initiation $\left(N_{i}=\alpha N_{f}\right.$, where $\alpha$ is the life fraction factor for the initiation stage) and (ii) crack propagation $\left(N_{i}=(1-\alpha) N_{f}\right)$ under constant amplitude stressing [123, 124]. This led to the double linear damage theory (DLDR) developed by Manson [125]. Manson et al. further developed the DLDR providing its refined form and moving to the damage curve approach (DCA) and the double damage curve approach (DDCA) [98, 126, 127]. These theories lean on the fundamental basis that the crack growth is the major manifestation of the damage [39] and were successfully applied on steels and space shuttles components (turbo pump blades and engines) $[128,129]$.

In order to account for the sequence effects, theories involving stress-controlled and strain-controlled [130-135] cumulative fatigue damage were combined under the socalled hybrid theories of Bui-Quoc and coworkers [136, 137]. Further improvements have been made by the same authors, in order to account for the sequence effect, when the cyclic loading includes different stress levels [138-141], temperature $[142,143]$, and creep [144-150].

Starting from the Palmgren-Miner rule, Zhu et al. [92] developed a new accumulation damage model, in order to account for the load sequence and to investigate how the stresses below the fatigue limit affect the damage induction. The specimens were subjected to two-stress as well as multilevel tests, and the authors established a fuzzy set method to predict the life and to analyze the evolution of the damage.

Hashin and Rotem [151], Ben-Amoz [152], Subramanyan [153], and Leipholz [154] proposed in the past a variety of life curve modification theories; also various nonlinear cumulative damage fatigue life prediction methods can be found in literature [155-158].

Recently Sun et al. [159] developed a cumulative damage model for fatigue regimes such as high-cycle and veryhigh-cycle regimes, including in the calculation some key parameters, such as (i) tensile strength of materials, (ii) sizes of fine grain area (FGA), and (iii) sizes of inclusions. Fatigue tests on GCr15 bearing steel showed a good agreement with this model [159].

\subsubsection{Fatigue Life Prediction at Variable Amplitude Loading.} Usually, the fatigue life prediction is carried out combining the material properties obtained by constant amplitude laboratory tests and the damage accumulation hypothesis by Miner and Palmgren [2,5]. Popular drawbacks of this method are the lack of validity of the Palmgren-Miner rule accounting for sequential effects, residual stresses, and threshold effects, but the biggest one is that, for loading cycles having amplitude below the fatigue limit, the resulting fatigue life according to the LDR is endless $(N=\infty)$ [160]. This is not acceptable, 
especially when variable amplitude loadings are applied [6, $161]$.

To overcome these issues, a variety of approaches has been proposed and can be found in literature [6, 162-168]. Among these, a stress-based approach was introduced by the Basquin relation $[162,163]$ :

$$
\sigma_{a}=\frac{(E \cdot \Delta \varepsilon)}{2}=\sigma_{f}^{\prime}\left(2 N_{f}\right)^{b}
$$

where $\sigma_{f}^{\prime}, E$, and $b$ are the fatigue strength coefficient, Young's modulus, and the fatigue strength exponent, respectively. The values of these three terms should be determined experimentally. A modification of the Basquin relation has been proposed by Gassner [164] in order to predict the failures of materials and components in service.

A strain-based approach was developed by means of the Coffin-Manson relation:

$$
\varepsilon_{a}^{p}=\frac{\left(\Delta \varepsilon^{p}\right)}{2}=\varepsilon_{f}^{\prime}\left(2 N_{f}\right)^{c}
$$

with $\varepsilon_{a}^{p}$, c, and $\varepsilon_{f}^{\prime}$ correspond to plastic strain amplitude, fatigue ductility exponent, and fatigue ductility, respectively $[51,169]$. The combination of (24) and (25) leads to a widely used total strain life expression:

$$
\varepsilon_{a}=\varepsilon_{a}^{p}+\varepsilon_{a}^{e}=\varepsilon_{f}^{\prime}\left(2 N_{f}\right)^{c}+\left(\frac{\sigma_{f}^{\prime}}{E}\right)\left(2 N_{f}\right)^{b},
$$

which has been implemented in fatigue life calculation software.

A different approach was proposed by Zhu et al. [92], who extended the Miner rule to different load sequences with the aid of fuzzy sets.

A detailed description of the effects of variable amplitude loading on fatigue crack growth is reported in the papers of Skorupa $[170,171]$.

Schütz and Heuler [167] presented a relative Miner rule, which is built using constant amplitude tests to estimate the parameter $\beta$; afterwards, spectrum reference tests are used to estimate the parameter $\alpha$. According to Miner's equation [2] (see (21)), for every reference spectrum test the failure occurs at

$$
D^{*}=\frac{N_{f}}{\widehat{\alpha}} \sum_{i} v_{i} S_{i}^{\widehat{\beta}}=\frac{N_{f}}{N_{\text {pred }}},
$$

where $N_{f}$ is the number of cycles to failure and $N_{\text {pred }}$ is the predicted life according to Palmgren-Miner. When more than one reference test is conducted, the geometric mean value is used. The failure is predicted at a damage sum of $D^{*}$ (not 1 as in the Palmgren-Miner equation), and the number of cycles to failure becomes

$$
N_{i}^{*}=D^{*} \cdot N_{i}
$$

A stochastic life prediction based on the Palmgren-Miner rule has been developed by Liu and Mahadevan [172]. Their model involves a nonliner fatigue damage accumulation rule and accounts for the fatigue limit dependence on loading, keeping the calculations as simple as possible. Considering an applied random multiblock loading, the fatigue limit is given by

$$
\sum \frac{n_{i}}{N_{i}} \sum \frac{1}{A_{i} / \omega_{i}+1-A_{i}}
$$

where $\omega_{i}$ is the loading cycle distribution and $A_{i}$ is a material parameter related to the level of stress.

Jarfall [173] and Olsson [165] proposed methods where the parameter $\alpha$ needs to be estimated from laboratory tests, while the exponent $\beta$ is assumed as known.

In the model suggested by Johannesson et al. [174], load spectra considered during laboratory reference tests were scaled to different levels. The authors defined $S_{\text {eq }}$ as the equivalent load amplitude for each individual spectrum, as

$$
S_{\mathrm{eq}}=\sqrt[\beta]{\sum_{k} v_{k} S_{k}^{\beta}},
$$

where $\beta$ is the Basquin equation $\left(N=\alpha S^{-\beta}\right)$ exponent. Considering the load amplitude $S_{k}$, its relative frequency of occurrence in the spectrum is expressed by $v_{k}$. The features of the load spectra, such as shape and scaling, are chosen in order to give different equivalent load amplitudes. The modified Basquin equation is then used to estimate the material parameters $\alpha$ and $\beta$ :

$$
N=\alpha S_{\mathrm{eq}}^{-\beta} .
$$

This estimation can be done combining the MaximumLikelihood method [175] with the numerical optimization. Considering a new load spectrum $\left\{\widehat{v}_{k}, \widehat{S}_{k} ; k=1,2, \ldots\right\}$, the fatigue life prediction results from the following calculations:

$$
\widehat{N}=\widehat{\alpha} \widehat{S}_{\text {eq }}^{-\widehat{\beta}} \quad \text { where } \widehat{S}_{\text {eq }}=\sqrt[\widehat{\beta}]{\sum_{k} \widehat{v}_{k} \widehat{S}_{k}^{\widehat{\beta}}} .
$$

Using continuum damage mechanics, Cheng and Plumtree [13] developed a nonlinear damage accumulation model based on ductility exhaustion. Considering that in general the fatigue failure occurs when the damage $D$ equals or exceeds a critical damage value $D_{C}$, the damage criterion can be written as

$$
D \geq D_{C} \text { fatigue failure. }
$$

In the case of multilevel tests, the cumulative damage is calculated considering that $n_{i}$ is the cycle having a level stress amplitude of $\Delta \sigma_{i}^{a}(i=1,2,3, \ldots)$, while $N_{i}$ is the number of cycles to failure. Therefore, the fatigue lives will be $N_{1}, N_{2}$, and $N_{3}$ at the respective stress amplitudes $\Delta \sigma_{1}^{a}, \Delta \sigma_{2}^{a}$, and $\Delta \sigma_{3}^{a}$. The damage for a single level test can be written as [13]

$$
D_{1}=D_{C}\left\{1-\left[1-\left(\frac{n_{1}}{N_{1}}\right)^{1 /(1+\psi)}\right]^{1 /\left(1+\beta_{1}\right)}\right\} \text {, }
$$


where $\psi$ is the ductility and $\beta$ is a material constant. The cumulative damage for a two-stage loading process can be therefore written as

$$
\frac{n_{1}}{N_{1}}+\left(\frac{n_{2}}{N_{2}}\right)^{\left\{(1-\varphi)\left[\left(1+\beta_{2}\right) /\left(1+\beta_{1}\right)\right]\right\}}=1 .
$$

In order to account for variable amplitude loading under the nominal fatigue limit, Svensson [15] proposed an extension of the Palmgren-Miner rule considering that the fatigue limit of a material decreases as the damage increases, owing to damage accumulation due to crack growth. The effects on fatigue behavior and cyclic deformation due to the load sequence were investigated for stainless steel 304L and aluminum alloy 7075-T6 by Colin and Fatemi [176], applying strain- and load-controlled tests under variable amplitude loading. The investigation under different load sequences showed that, for both materials, the $\mathrm{L}-\mathrm{H}$ sequence led to a bigger sum (longer life) compared to the $\mathrm{H}-\mathrm{L}$ sequence.

A few models explaining the macrocrack growth retardation effect under variable amplitude loading can be found in literature [177-183], also combined with crack closure effects [179].

Recently, starting from the model proposed by Kwofie and Rahbar $[184,185]$ using the fatigue driving stress parameter (function of applied cyclic stress, number of loading cycles, and number of cycles to failure), Zuo et al. [186] suggested a new nonlinear model for fatigue life prediction under variable ampitude loading conditions, particularly suitable for multilevel load spectra. This model is based on a proper modification of the Palmgren-Miner's linear damage accumulation rule, and the complete failure (damage) of a component takes place when

$$
D=\sum_{i=1}^{n} \beta_{i} \frac{\ln N_{f i}}{\ln N_{f 1}}=1,
$$

where

$$
\beta_{i}=\frac{n_{i}}{N_{f i}}
$$

$\beta_{i}$ is the expended life fraction at the loading stress $S_{i}$, and $N_{f i}$ is the failure life of $S_{i}$ [184]. Compared with the MarcoStarkey [90] LDR modification, the present model is less computationally expensive and is easier to use compared to other nonlinear models. In order to account for random loading conditions, Aïd et al. [160] developed an algorithm based on the $S-N$ curve, further modifed by Benkabouche et al. [187].

\subsubsection{Fatigue Life Prediction under Multiaxial Loading Condi-} tions. Generally speaking, a load on an engineering component in service can be applied on different axis contemporary (multiaxial), instead of only one (uniaxial). Moreover, the loads applied on different planes can be proportional (in phase), or nonproportional (out of phase). Other typical conditions that can vary are changes in the principal axes, or a rotation of these with respect to time, a deflection in the crack path, an overloading induced retardation effect, a nonproportional straining effect, a multiaxial stress/strain state, and many more [188-190]. These factors make the multiaxial fatigue life prediction very complicated. A number of theories and life predictions addressing this issue have been proposed in the past $[15,191-215]$.

For the multiaxial fatigue life prediction, critical plane approaches linked to the fatigue damage of the material can be found in literature; these approaches are based either on the maximum shear failure plane or on the maximum principal stress (or strain) failure plane [190]. The critical plane is defined as the plane with maximum fatigue damage and can be used to predict proportional or nonproportional loading conditions [216]. The prediction methods can be based on the maximum principal plane, or on the maximum shear plane failure mode, and also on energy approaches. The models can be classified into three big groups as (i) stress-based models, involving the Findley et al. [217] and McDiarmid [218] parameters, (ii) strain-based models (i.e., Brown and Miller [195]), and (iii) stress- and strain-based models, involving the Goudarzi et al. [194] parameter for shear failure and the Smith-Watson-Topper (SWT) parameter for tensile failure [216, 219]. Stress-based damage models are useful under high-cycle fatigue regimes since plastic deformation is almost negligible, while strain-based criteria are applied under low-cycle fatigue regimes but can be also considered for the high-cycle fatigue.

The application of these methodologies on the fatigue life prediction of Inconel 718 has been recently made by Filippini et al. [220].

Among all the possible multiaxial fatigue criteria, those belonging to Sines and Waisman [221] and Crossland [222] resulted in being very easy to apply and have been extensively used for engineering design [223].

In the case of steels, by combining the Roessle-Fatemi method with the Fatemi-Socie parameter it is possible to estimate the fatigue limit for loadings being in or out of phase, and the hardness is used as the only material's parameter $[216,224]$.

In particular, Carpinteri and Spagnoli [206] proposed a prediction method for hard metals based on the critical plane determination; a nonlinear combination of the shear stress amplitude and the maximum normal stress acting on the critical plane led to the fatigue life prediction. According to (37), the multiaxial stress state can be transformed into an equivalent uniaxial stress:

$$
\sigma_{\mathrm{eq}}=\sqrt{N_{\max }^{2}+\left(\frac{\sigma_{a f}}{\tau_{a f}}\right)^{2} C_{a}^{2}}
$$

where $C_{a}$ is the shear stress amplitude, $N_{\max }$ is the maximum normal stress, and $\sigma_{a f} / \tau_{a f}$ is the endurance limit ratio [206]. Further modifications proposed for this model are available in literature [225-227].

Papadopoulos [228] also proposed a critical plane model in order to predict multiaxial high-cycle fatigue life using a stress approach $[218,229,230]$. 
For high-cycle fatigue, Liu and Mahadevan [208] developed a criterion based on the critical plane approach, but this model can be even used for the prediction of fatigue life under different loading conditions, such as (i) in phase, (ii) out of phase, and (iii) constant amplitude. The same authors [231] proposed also a unified characteristic plane approach for isotropic and anisotropic materials where the cracking information is not required.

Bannantine and Socie [191] stated that there is a particular plane which undergoes the maximum damage and this is where the fatigue damage events occur. All the strains are projected on the considered plane, and the normal strain (shear strain) is then cycle-counted using the rainflowcounting algorithm [232]. The strain to be counted is selected according to the predominant cracking mode for the considered material. The fatigue damage connected with every cycle can be calculated with the tensile mode (see (38)) or the shear mode (see (39)):

$$
\begin{aligned}
\frac{\Delta \varepsilon}{2} \sigma_{\max } & =\frac{\left(\sigma_{f}^{\prime}\right)^{2}}{E}\left(2 N_{f}\right)^{2 b}+\sigma_{f}^{\prime} \varepsilon_{f}^{\prime}\left(2 N_{f}\right)^{b+c} \\
\frac{\Delta \bar{\gamma}}{2} & \equiv \frac{\Delta \gamma}{2}\left(1+\frac{\sigma_{n, \max }}{\sigma_{y}}\right) \\
& =\frac{\left(\tau_{f}^{*}\right)^{2}}{G}\left(2 N_{f}\right)^{b}+\gamma_{f}^{*}\left(2 N_{f}\right)^{c}
\end{aligned}
$$

where for each cycle $\Delta \varepsilon$ is the strain range and $\sigma_{\max }$ is the maximum normal stress. The maximum shear strain range is given by $\Delta \gamma$, while the maximum normal stress on the maximum shear plane is expressed by $\sigma_{n \text {,max }}$. Other constants and symbols are explained deeply in the paper of Goudarzi et al. [194], where a modification of Brown and Miller's critical plane approach [195] was suggested. It is worth mentioning that, among the conclusions reached by Fatemi and Socie [195], it is stated that since by varying the combinations of loading and materials different cracking modes are obtained, a theory based on fixed parameters would not be able to predict all the multiaxial fatigue situations. Therefore, this model can be applied only to combinations of loading and materials resulting in a shear failure. The Bannantine and Socie method [191] is unable to account for the cracks branching or for the consequent involvement of the multistage cracks growth process. Therefore, this model should be considered only when the loading history is composed of repeated blocks of applied loads characterized by short length, because the cracks would grow essentially in one direction only [189].

Given that cycling plastic deformation leads to fatigue failure, Wang and Brown $[189,192,233,234]$ identified that a multiaxial loading sequence can be assimilated into cycles, and therefore the fatigue endurance prediction for a general multiaxial random loading depends on three independent variables: (i) damage accumulation, (ii) cycle counting, and (iii) damage evaluation for each cycle. Owing to the key assumption of the fatigue crack growth being controlled by the maximum shear strain, this method has been developed only for medium cycle fatigue (MCF) and low cycle fatigue
(LCF) $[189,233]$. Application of the Wang and Brown criteria showed that, allowing changes of the critical plane at every reversal, a loading history composed of long blocks is suitable for fatigue life prediction [192].

It is worth mentioning that a load path alteration (torsion before tension or tension before torsion, etc.) in multiaxial fatigue strongly affects the fatigue life [235-237].

A situation of constant amplitude multiaxial loading (proportional and nonproportional) was used to develop a new fatigue life prediction method by Papadopoulos [228].

Aid et al. [238] applied an already developed Damage Stress Model [160, 239-241] for uniaxial loadings to study a multiaxial situation, combining it with the material's strength curve ( $S$ - $N$ curve) and the equivalent uniaxial stress.

More recently, Ince and Glinka [242] used the generalized strain energy (GSE) and the generalized strain amplitude (GSA) as fatigue damage parameters, for multiaxial fatigue life predictions. Considering the GSA, the multiaxial fatigue damage parameter can be expressed as follows:

$$
\begin{aligned}
\frac{\Delta \varepsilon_{\mathrm{gen}}^{*}}{2} & =\left(\frac{\tau_{\max }}{\tau_{f}^{\prime}} \frac{\Delta \gamma^{e}}{2}+\frac{\Delta \gamma^{p}}{2}+\frac{\sigma_{n, \max }}{\sigma_{f}^{\prime}} \frac{\Delta \varepsilon_{n}^{e}}{2}+\frac{\Delta \varepsilon_{n}^{p}}{2}\right)_{\max } \\
& =f\left(N_{f}\right),
\end{aligned}
$$

where the components of the shear $(\tau, \gamma)$ and normal $(\sigma, \varepsilon)$ strain energies can be spotted. Application of this model to Incoloy 901 super alloy, 7075-T561 aluminum alloy, 1045 HRC 55 steel, and ASTM A723 steel gave good agreement with experimental results [242].

A comparison of various prediction methods for multiaxial variable amplitude loading conditions under highcycle fatigue has been recently performed by Wang et al. [243]. Results showed that, for aluminum alloy 7075-T651, the maxium shear stess together with the main auxiliary channels counting is suitable for multiaxial fatigue life predictions.

\subsection{Energy-Based Theories for Fatigue Life Prediction. As} mentioned before in this paragraph, linear damage accumulation methods are widely used owing to their clarity. These methods are characterized by three fundamental assumptions: (i) at the beginning of each loading cycle, the material acts as it is in the virgin state; (ii) the damage accumulation rate is constant over each loading cycle; and (iii) the cycles are in ascending order of magnitude, despite the real order of occurrence [18]. These assumptions allow predicting the fatigue failure for high cycles (HCF) in a sufficiently appropriate manner, but the same cannot be said for the low-cycle fatigue (LCF), where the dominant failure mechanism is identified as the macroscopic strain.

In order to describe and predict the damage process and, therefore, the fatigue life under these two regimes, a unified theory based on the total strain energy density was presented by Ellyin and coworkers [12, 244, 245].

The total strain energy per cycle can be calculated as the sum of the plastic $\left(\Delta W^{p}\right)$ and elastic $\left(\Delta W^{e}\right)$ strain energies:

$$
\Delta W^{t}=\Delta W^{p}+\Delta W^{e}
$$




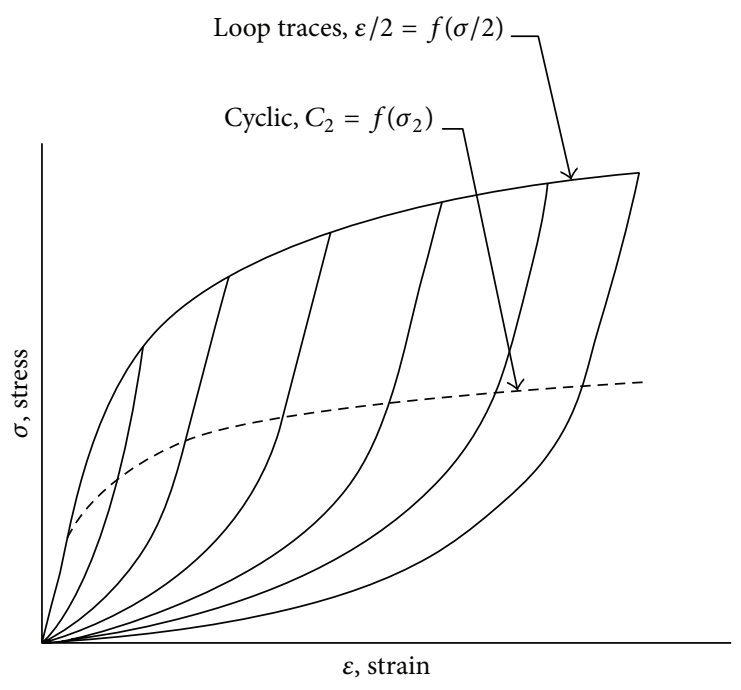

(a) Masing-type deformation

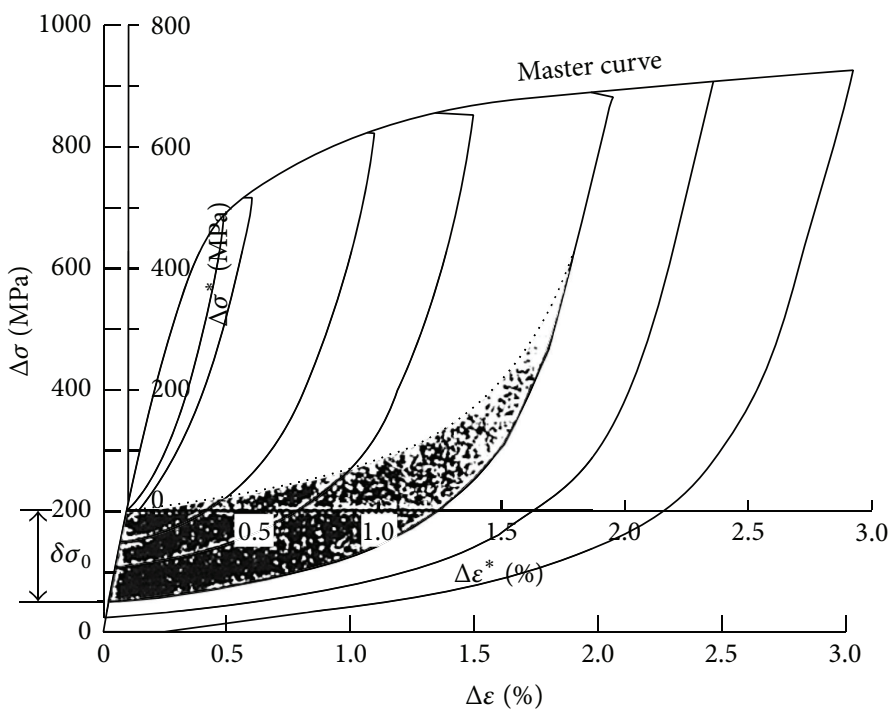

(b) Non-Masing type deformation

Figure 5: Materials exhibiting hysteresis loops with (a) Masing-type deformation and (b) non-Masing type deformation (Adapted from [39]).

The plastic portion of strain is the one causing the damage, while the elastic portion associated with the tensile stress facilitates the crack growth [12]. This theory can be applied to Masing and non-Masing materials [246] (Figure 5) and, in both cases, a master curve can be drawn (translating loop along its linear response portion, for the non-Masing materials). follows:

Therefore, the cyclic plastic strain can be written as

Non-Masing behavior is

$$
\Delta W^{p}=\frac{1-n^{*}}{1+n^{*}}\left(\Delta \sigma-\delta \sigma_{0}\right) \Delta \varepsilon^{p}+\delta \sigma_{0} \Delta \varepsilon^{p}
$$

Ideal Masing behavior is

$$
\Delta W^{p}=\frac{1-n^{\prime}}{1+n^{\prime}} \Delta \sigma \Delta \varepsilon^{p}
$$

where $n^{*}$ and $n^{\prime}$ are the cyclic strain hardening exponents of the mater curve and of the idealized Masing material, respectively. Further improvements to this theory have been made, in order to account for the crack initiation and propagation stages [245-247].

Concerning the low-cycle fatigue (LCF), Paris and Erdogan [47] proposed an energy failure criterion based on the energy expenditure during fatigue crack growth.

Interesting energy-based theories were proposed also by Xiaode et al. [248], after performing fatigue tests under constant strain amplitude and finding out that a new cyclic stress-strain relation could have been suggested, given that the cyclic strain hardening coefficient varies during the tests as introduced also by Leis [249].
The theory of Radhakrishnan [250, 251] postulating the proportionality between plastic strain energy density and crack growth rate is worth mentioning. The prediction of the life that remains at the $m$-load variation can be expressed as

$$
r_{m}=1-\sum_{i=1}^{m-1} \frac{W_{f i}}{W_{f m}} r_{i}
$$

where $W_{f i}$ and $W_{f m}$ are the total plastic strain energy at failure for the $i$ th and the $m$ th levels, respectively, under cycles at constant amplitude. In the case of harmonic loading cycles, Kliman [252] proposed a similar concept for fatigue life prediction.

Based on the energy principle and on a cumulative damage parameter, Kreiser et al. [18] developed a nonlinear damage accumulation model (NLDA), which is particularly suitable for materials and structures subjected to loadings of high amplitude applied for low cycles (substantial plastic strain). This model, starting from the Ellyin-Golos approach [12], accounts for the load history sequence which reflects in the progressive damage accumulation. Considering the LCF Coffin-Manson relation [253], the plastic strain range was considered as an appropriate damage parameter for metals showing stable hysteresis, while in the case of unstable hysteresis also the stress range must be included [18, 254, 255]. The cumulative damage function $(\varphi)$ depends on a material parameter $\left(p_{m}\right)$ and on the cumulative damage parameter $(\psi)$, and it can be defined using the ratio between the plastic energy density $\left(\Delta W_{p}\right)$ and the positive (tensile) elastic strain energy density $\left(\Delta W_{e}^{+}\right)$:

$$
\varphi=f\left(\psi, p_{m}\right)=\frac{1}{\log 10\left(\Delta W_{p} / \Delta W_{e}^{+}\right)} .
$$


With the universal slopes method, Manson [256, 257] derived the following equation for the fatigue life prediction:

$$
\Delta \varepsilon=\Delta \varepsilon_{e}+\Delta \varepsilon_{p}=3.5 \frac{\sigma_{B}}{E} N_{f}^{-0.12}+\varepsilon_{f}^{0.6} N_{f}^{-0.6},
$$

where $\varepsilon_{f}$ is the fracture ductility and $\sigma_{B}$ is the tensile strength. As can be seen in (39), the values of the slopes have been universalized by Manson and are equal to -0.6 for the elastic part and -0.12 for the plastic part.

Considering a wide range of materials steels, aluminum and titanium alloys, Muralidharan and Manson [258] derived a modified universal slopes method, in order to estimate the fatigue features only from the tensile tests data obtained at temperatures in the subcreep range. This method gives a higher accuracy than the original one and is described by the following equation:

$$
\begin{aligned}
\Delta \varepsilon= & 1.17\left(\frac{\sigma_{B}}{E}\right)^{0.832} N_{f}^{-0.09} \\
& +0.0266 \varepsilon_{f}^{0.155}\left(\frac{\sigma_{B}}{E}\right)^{-0.53} N_{f}^{-0.56} .
\end{aligned}
$$

Obtaining the elastic slope from tensile strength, Mitchell [259] proposed a modified elastic strain life curve. A further modification of this method was proposed by Lee et al. [260], in order to estimate the life of some Ni-Based superalloys exposed to high temperatures.

Bäumel and Seeger [261] established a uniform materials law that uses only the tensile strength as input data. In the case of some steels (low-alloyed or unalloyed), the equation can be expressed as follows:

$$
\begin{aligned}
\frac{\Delta \varepsilon}{2} & =\frac{\Delta \varepsilon_{e}}{2}+\frac{\Delta \varepsilon_{p}}{2} \\
& =1.50 \frac{\sigma_{B}}{E}\left(2 N_{f}\right)^{-0.087}+0.59 \psi\left(N_{f}\right)^{-0.58},
\end{aligned}
$$

where

$$
\begin{aligned}
& \psi=1 \quad \text { when } \frac{\sigma_{B}}{E} \leq 0.003 \\
& \psi=1.375-125.0 \frac{\sigma_{B}}{E} \quad \text { when } \frac{\sigma_{B}}{E}>0.003 .
\end{aligned}
$$

For titanium and aluminum alloys, the equation is modified as follows:

$$
\begin{aligned}
\frac{\Delta \varepsilon}{2} & =\frac{\Delta \varepsilon_{e}}{2}+\frac{\Delta \varepsilon_{p}}{2} \\
& =1.67 \frac{\sigma_{B}}{E}\left(2 N_{f}\right)^{-0.095}+0.35\left(2 N_{f}\right)^{-0.69} .
\end{aligned}
$$

The application of these techniques to the prediction of the fatigue life of gray cast iron under conditions of high temperatures has been recently conducted by K.-O. Lee and S. B. Lee [262].

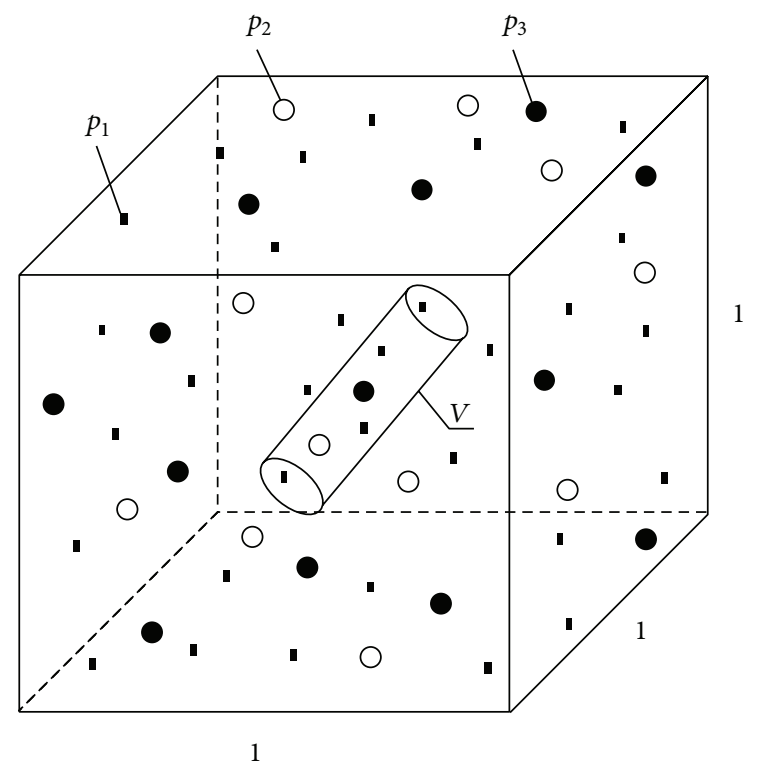

FIGURE 6: Three groups of defects characterized by individual probabilities $p_{1}=0.2, p_{2}=0.3$, and $p_{3}=0.4$ of fatigue crack initiation used in the Monte Carlo simulations. The region with volume $V$ is characterized by a fatigue stress range $\Delta \sigma$ [91].

Under multiaxial loading conditions, the fatigue life can be also estimated using energy criteria based on elastic energy $[40,263,264]$, plastic energy [40, 265-267], or a combination of these two [219, 268-276].

2.6. Probability Distribution of Fatigue Life Controlled by Defects. Todinov [91] proposed a method to determine the most deleterious group of defects affecting the fatigue life. For a given material, the effect of discontinuities on the cumulative fatigue distribution can be calculated [91]. As already proposed in a previous work by the same author [78], the defects have been divided into groups according to their type and size, each group being characterized by a different average fatigue life. The individual probability $p_{i}$ depends on the fatigue stress range $\Delta \sigma$ but not on other groups of defects.

Considering a volume region $V$ (Figure 6) subjected to fatigue loading and having a fatigue stress range $\Delta \sigma$, the probability that at least one fatigue crack will start in this volume can be obtained by subtracting from the unity the no-fatigue crack initiation (in $V$ ) probability. Therefore, the probability equation $P_{(r)}^{0}$ can be written as follows:

$$
P_{(r)}^{0}=\frac{(\mu V)^{r} e^{-\mu V}}{r !}[1-p(\Delta \sigma)]^{r}
$$

where $\mu$ represents the defects' density reducing the fatigue life to a number of cycles lower than $x$. The absence of fatigue crack initiation at $\Delta \sigma$ can be defined by

$$
P^{0}=\sum_{r=0}^{\infty} P_{(r)}^{0}=\sum_{r=0}^{\infty} \frac{(\mu V)^{r} e^{-\mu V}}{r !}[1-p(\Delta \sigma)]^{r}
$$


which can be simplified as follows:

$$
\begin{aligned}
P^{0} & =e^{-\mu V} \sum_{r=0}^{\infty} \frac{[\mu V(1-p(\Delta \sigma))]^{r}}{r !}=e^{-\mu V} e^{\mu V[1-p(\Delta \sigma)]} \\
& =e^{-\mu V \cdot p(\Delta \sigma)}
\end{aligned}
$$

Equation (53) shows how to obtain the fatigue crack initiation probability $\left(P^{0}\right)$ at a fatigue stress range $\Delta \sigma$. This probability $P^{0}$ equals the probability of at least a single fatigue crack initiation in a space volume $V$ and is given by

$$
G(\Delta \sigma)=1-e^{-V \sum_{i=1}^{M} \mu_{i} p_{i}(\Delta \sigma)}
$$

The equivalence in (54) leads to a fatigue life smaller than or equal to $x$ cycles as reported in

$$
F(X \leq x)=1-e^{-V \sum_{x} \mu_{x} p_{x}(\Delta \sigma)} .
$$

This calculation is extended only to the defects' groups inducing a fatigue life equal to or smaller than $x$ cycles. The same groups are considered for the expected fatigue life $\bar{L}$ determination, obtained by calculating the weighted average of the fatigue lives $L_{i}$ :

$$
\bar{L}=f_{0} L_{0}+\sum_{i=1}^{M} f_{i} L_{i}
$$

where $f_{i}(i=0 ; M)$ are the fatigue failure frequencies.

The most influential group of defects for the fatigue life is determined by calculating the expected fatigue life rise, when the $i$ th group of defects is removed:

$$
\Delta \bar{L}_{i}=-f_{i} L_{i}+\frac{G_{i}}{1-G_{i}}\left(f_{0} L_{0}+\sum_{j=i+1}^{M} f_{j} L_{j}\right)
$$

Therefore, the largest value of $\Delta \bar{L}_{m}$ corresponding to the removal of the $m$-indexed group of defects identifies the most deleterious ones.

$\mathrm{Su}$ [277] studied the connection between the microstructure and the fatigue properties using a probabilistic approach. The key assumption in this case is that the fatigue life decreases monotonically with the size of the local microstructural features which are responsible for the generation of the fatigue crack. Addressing the cast aluminum topic, $\mathrm{Su}$ [277] obtained that micropores are the crucial feature affecting the fatigue life. It must be stressed out that the local microstructural feature having the highest impact on the fatigue properties depends on the particular material (e.g., for cast aluminum alloy 319 [278], fatigue cracks are used to initiate from micropores [278-281]). Caton et al. [281] found a correlation between the critical pore size and the fatigue life, the latter being monotonically decreasing with the porosity size. Therefore, the growth of a fatigue crack can be calculated as follows:

$$
\frac{d a}{d N}=C\left[\left(\varepsilon_{\max } \frac{\sigma_{a}}{\sigma_{y}}\right)^{s} a\right]^{t}
$$

where $a$ is the crack length, whose initial value is equal to the pore diameter of the discontinuity that generates the crack. Integrating (58), the relationship between the initial pore size and the fatigue life can be written as follows:

$$
\begin{aligned}
& N=K\left(a_{f}^{-t+1}-D_{0}^{-t+1}\right) \\
& \text { where } K=\frac{1}{1-t} C^{-1}\left(\varepsilon_{\max } \frac{\sigma_{a}}{\sigma_{y}}\right)^{-s t},
\end{aligned}
$$

where $D_{0}$ is the crack length, while $C, s$, and $t$ are material parameters. $\sigma_{a}, \sigma_{y}$, and $\varepsilon_{\max }$ are the alternating stress magnitude, the yield stress, and the maximum strain, respectively. It can be useful to invert (58) in order to express the critical pore dimension as a function of the fatigue life:

$$
D_{0}=\left[a_{f}^{-t+1}-(1-t) C\left(\varepsilon_{\max } \frac{\sigma_{a}}{\sigma_{y}}\right)^{s t} N\right]^{1 /(1-t)}
$$

2.7. Continuum Damage Mechanics (CDM) Models for Fatigue Life Prediction. Starting from the concept that the accumulation of damage due to environmental conditions and/or service loading is a random phenomenon, Bhattacharaya and Ellingwood [27, 282] developed a continuum damage mechanics (CDM) based model for the fatigue life prediction. In particular, starting from fundamental thermodynamic conditions they proposed a stochastic ductile damage growth model [27]. The damage accumulation equations resulting from other CDM-based approaches suffer usually from a lack of continuity with the first principles of mechanics and thermodynamics [283], owing to their start from either a dissipation potential function or a kinetic equation of damage growth. Battacharaya and Ellingwood [27] considered instead the dissipative nature of damage accumulation and accounted for the thermodynamics laws that rule it [284]. If a system in diathermal contact with a heat reservoir is considered, the rate of energy dissipation can be calculated from the first two laws of thermodynamics and can be written as follows according to the deterministic formulation:

$$
\Gamma \equiv-\dot{K}_{E}+\dot{W}-\frac{\partial \Psi}{\partial \underline{\varepsilon}} \cdot \underline{\dot{\varepsilon}}-\frac{\partial \Psi}{\partial D} \dot{D} \geq 0,
$$

where $K_{E}$ is the kinetic energy and $W$ is the work done on the system. The Helmholtz free energy $\Psi(\theta, \underline{\varepsilon}, D)$ is a function of the damage variable $D$, the symmetric strain tensor $(\underline{\varepsilon})$, and the temperature $(\theta)$.

The system is at the near equilibrium state and is subjected to continuous and rapid transitions of its microstates, causing random fluctuations of state variables around their mean values. Therefore, the stochastic approach [27] is the most 
suitable to describe the free energy variation and as per (61), the first one can be written as follows:

$$
\delta \Psi(t)=\delta \int_{t_{0}}^{t}\left(\dot{W}-\dot{K}_{E}\right) d t-\delta \int_{t_{0}}^{t} \Gamma d t+\delta B(t) \approx 0,
$$

where $B(t)$ represents the free energy random fluctuation, $t_{0}$ is the initial equilibrium state, and $t$ is an arbitrary instant of time $\left(t>t_{0}\right)$. For a body that undergoes an isotropic damage due to uniaxial loading, the following can be assumed:

$$
\sigma_{\infty}+\psi_{D} \frac{d D}{d \varepsilon}+s_{b}=0
$$

where $\sigma_{\infty}$ is the far-field stress acting normal to the surface and $\psi_{D}$ is the partial derivative of the free energy per unit volume $(\psi)$ with respect to $D$. The quantity $s_{b}$, which is equal to $\left(\partial^{2} B\right) /(\partial \varepsilon \partial V)$, represents the random fluctuation imposed on the stress field existing within the deformable body. Assuming that $s_{b}$ is described by the Langevin equation, it is possible to write what follows:

$$
\frac{d s_{b}}{d \varepsilon}=-c_{1} s_{b}+\sqrt{c_{2} \xi(\varepsilon)}
$$

where $c_{1}$ and $c_{2}$ are positive constants, while $\xi(\varepsilon)$ corresponds to the Gaussian white noise indexed with the strain. In this particular case, three key assumptions are necessary: (i) $s_{b}$ should be a zero-mean process characterized by equiprobable positive and negative values, (ii) compared to the macroscopic rate of damage change, the fluctuation rate is extremely rapid, and (iii) the $s_{b}$ mean-square fluctuation should be time or strain independent [27]. Considering the scale of time/strain typical of structural mechanics, the fluctuations are extremely rapid and, therefore, the damage growth stochastic differential equation can be written as follows [285]:

$$
d D(\varepsilon)=-\frac{\sigma_{\infty}}{\psi_{D}} d \varepsilon-\frac{\sqrt{c_{2} / c_{1}}}{\psi_{D}} d W(\varepsilon),
$$

where $W(\varepsilon)$ is the standard Wiener process. This formulation allows considering the presence of negative damage increments over a limited time interval at the microscale, even though the calculated increment of damage should be nonnegative in absence of repair.

According to Battacharaya and Ellingwood [27], in presence of a uniaxial monotonic loading, the free energy per unit volume can be calculated as follows:

$$
\psi=\int \sigma d \varepsilon-\gamma
$$

In (66), $\gamma$ is the energy associated with the defects formation (per unit volume) due to damage evolution. With the aid of the Ramberg-Osgood monotonic stress-strain relations, the total strain can be estimated as follows:

$$
\varepsilon=\frac{\widetilde{\sigma}}{E}+\left(\frac{\widetilde{\sigma}}{K}\right)^{M}
$$

where the first term is the elastic strain $\left(\varepsilon_{e}\right)$ and the second is the plastic strain $\left(\varepsilon_{p}\right)$, while $M$ and $K$ are the hardening exponent and modulus, respectively. The second term of (66) can be instead estimated as

$$
\gamma=\frac{3}{4} \sigma_{f} D
$$

where $\sigma_{f}$ is the failure strain, assuming that (i) discontinuities are microspheres not interacting with each other and having different sizes, (ii) stress amplifications can be neglected, and (iii) there is a linear relation between force and displacement at the microscale. Equation (65) can be rewritten as follows:

$$
\begin{aligned}
d D\left(\varepsilon_{p}\right)= & A\left(\varepsilon_{p}\right)\left(1-D\left(\varepsilon_{p}\right)\right) d \varepsilon_{p} \\
& +B\left(\varepsilon_{p}\right) d W\left(\varepsilon_{p}\right)
\end{aligned}
$$

where $A$ and $B$ are coefficients depending on $\varepsilon_{p}, \sigma_{f}, M$, $K$, and $\varepsilon_{0}$. If the materials properties $\underline{\Omega}=\left\{\varepsilon_{0}, \sigma_{f}, K, M\right\}$ are considered deterministic and $D_{0}=D\left(\varepsilon_{0}\right)$ is the initial damage that can be either deterministic or Gaussian, the result is that damage is a Gaussian process as defined by the damage variable [27].

Concerning nonlinear models, Dattoma et al. [286] proposed theory applied on a uniaxial model based on continuum damage mechanics [287]. In the formulation of this nonlinear model [286] the authors started from the nonlinear load dependent damage rule, firstly formulated by Marco and Starkey [90] as follows:

$$
D=\sum_{i=1}^{n} r_{i}^{x_{i}}
$$

where $x_{i}$ is a coefficient depending on the $i$ th load. The experimental results showed a good agreement with the data calculated with this method, although for each load it is necessary to recalculate the $x_{i}$ coefficients.

The mechanical deterioration connected to fatigue and creep through the continuum damage theory was introduced by Kachanov [288] and Rabotnov [289]. Later, Chaboche and Lemaitre [290, 291] formulated a nonlinear damage evolution equation, so that the load parameters and the damage variable $D$ result in being nondissociable:

$$
\delta D=f(D, \sigma) \delta n,
$$

where $n$ is the number of cycles at a given stress amplitude and $\sigma$ is the stress amplitude [291, 292].

This fatigue damage can be better defined as follows:

$$
\begin{aligned}
\delta D= & {\left[1-(1-D)^{\beta+1}\right]^{\alpha\left(\sigma_{\max }, \sigma_{\mathrm{med}}\right)} } \\
& \cdot\left[\frac{\sigma_{a}}{M_{0}\left(1-b \sigma_{\mathrm{med}}\right)(1-D)}\right]^{\beta} \delta n,
\end{aligned}
$$

where $\beta, M_{0}$, and $b$ depend on the material, while $\alpha$ depends on the loading. $\sigma_{\max }$ and $\sigma_{\text {med }}$ are the maximum and the mean stress of the cycle, respectively. The stress amplitude $\sigma_{a}$ is calculated as $\sigma_{a}=\sigma_{\max }-\sigma_{\text {med }}$. This approach has been 
adopted by various authors [13, 14, 33, 292] with integrations and modifications. All these CDM models were developed for the uniaxial case, but also thermomechanical models based on mechanics of the continuous medium can be found in literature [11, 293]. According to Dattoma et al. [286] the number of cycles to failure $\left(N_{f}\right)$ for a given load can be written as follows:

$$
N_{f}=\frac{1}{1-\alpha} \frac{1}{1+\beta}\left[\frac{\sigma_{a}}{M_{0}}\right]^{-\beta},
$$

which is a good approximation of the linear relation between $\log S$ and $\log N$ [33]. The main result highlighted by this formulation is that damage is an irreversible degradation process which increases monotonically with the applied cycles (see (74)). Moreover, the higher the load, the larger the fatigue damage (see (74)):

$$
\begin{aligned}
& \frac{\delta D}{\delta n}>0, \\
& \frac{\delta^{2} D}{\delta n \delta \sigma}>0 .
\end{aligned}
$$

This model was employed for the fatigue life calculation of a railway axle built with $30 \mathrm{NiCrMoV} 12$, running onto a European line for about $3000 \mathrm{~km}$, taking care of its load history. Final experimental tests were conducted with high-low, low-high, and random sequence using cylindrical specimens. Results showed that this model has a good capacity to predict the final rupture when complex load histories are considered $[286,287]$.

A lot of fatigue life prediction theories based on nonlinear continuum damage mechanics can be found in literature [13, 14, 39, 294-298], addressing various situations such as fatigue combined to creep, uniaxial fatigue, and ductile failure.

2.8. Other Approaches. Addressing the particular case of aluminum alloys, Chaussumier and coworkers developed a multicrack model for fatigue life prediction, using the coalescence and long and short crack growth laws [299]. Based on this work, further studies on the prediction of fatigue life of aluminum alloys have been conducted by the same authors [300, 301]. The approach used in the paper of Suraratchai et al. [300] is worth mentioning, where the effect of the machined surface roughness on aluminum alloys fatigue life was addressed. Considering an industrial frame, the particular purpose of this work was the fatigue life prediction of components when changing machining parameters and processes, in order to avoid tests that could be expensive and time-consuming. Accounting for other methods present in literature [302-309] that usually consider the surface roughness as a notch effect in terms of stress, the theory developed by Suraratchai et al. [299] modeled how the geometric surface condition affects the fatigue properties of structures. In this theory [299] the surface roughness is considered responsible for the generation of a local stress concentration, controlling the possible surface crack propagation or nonpropagation.

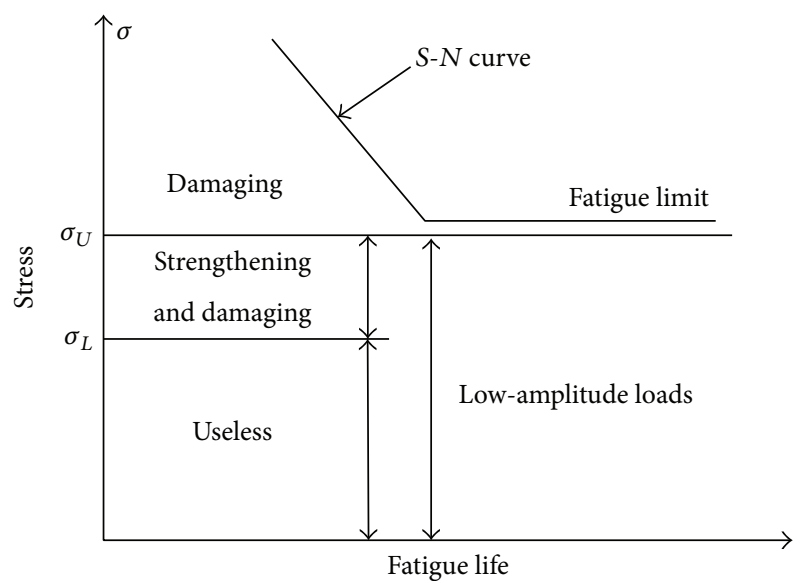

FIGURE 7: Load region and its strengthening and damaging effect (adapted from [92]).

Thermomechanical fatigue (TMF), mainly related to single crystal superalloys operating at high temperatures, was studied by Staroselsky and Cassenti [310], and the combination of creep, fatigue, and plasticity was also addressed [311]. The low-cycle fatigue-creep (LCF-C) prediction has been studied by several authors [70, 312-317] for steels and superalloys applications. Strain range partitioning- (SRP-) based fatigue life predictions [318-320] or frequency modified fatigue life (FMFL) [320, 321] can be also found in this field.

Zhu et al. [92] used the fuzzy set method to predict the fatigue life of specimen under loadings slightly lower than the fatigue limit, accounting for strengthening and damaging effects, as well as for the load sequence and load interaction. A schematic representation of this theory is reported in Figure 7.

Other particular fatigue life prediction models can be found in literature, based on significant variations of physical and microstructural properties [322-327], on thermodynamic entropy [328, 329], and on entropy index of stress interaction and crack severity index of effective stress [330].

Even though a look at the frequency domain for the fatigue life estimation has been given in the past [331-334], recently new criteria have been developed by several authors, highlighting the rise of a brand new category of fatigue life estimation criteria that will surely get into the engineering spotlights [335-342].

\section{Summary}

Starting from the introduction of the linear damage rule, a huge number of fatigue life prediction models have been proposed, yet none of these can be universally accepted. Authors all over the world put efforts into modifying and extending the already existing theories, in order to account for all the variables playing key roles during cyclic applications of loadings. The complexity of the fatigue problem makes this topic actual and interesting theories using new approaches arise continuously. The range of application of each model varies from case to case and, depending on the particular application and to the reliability factors that must be considered, 


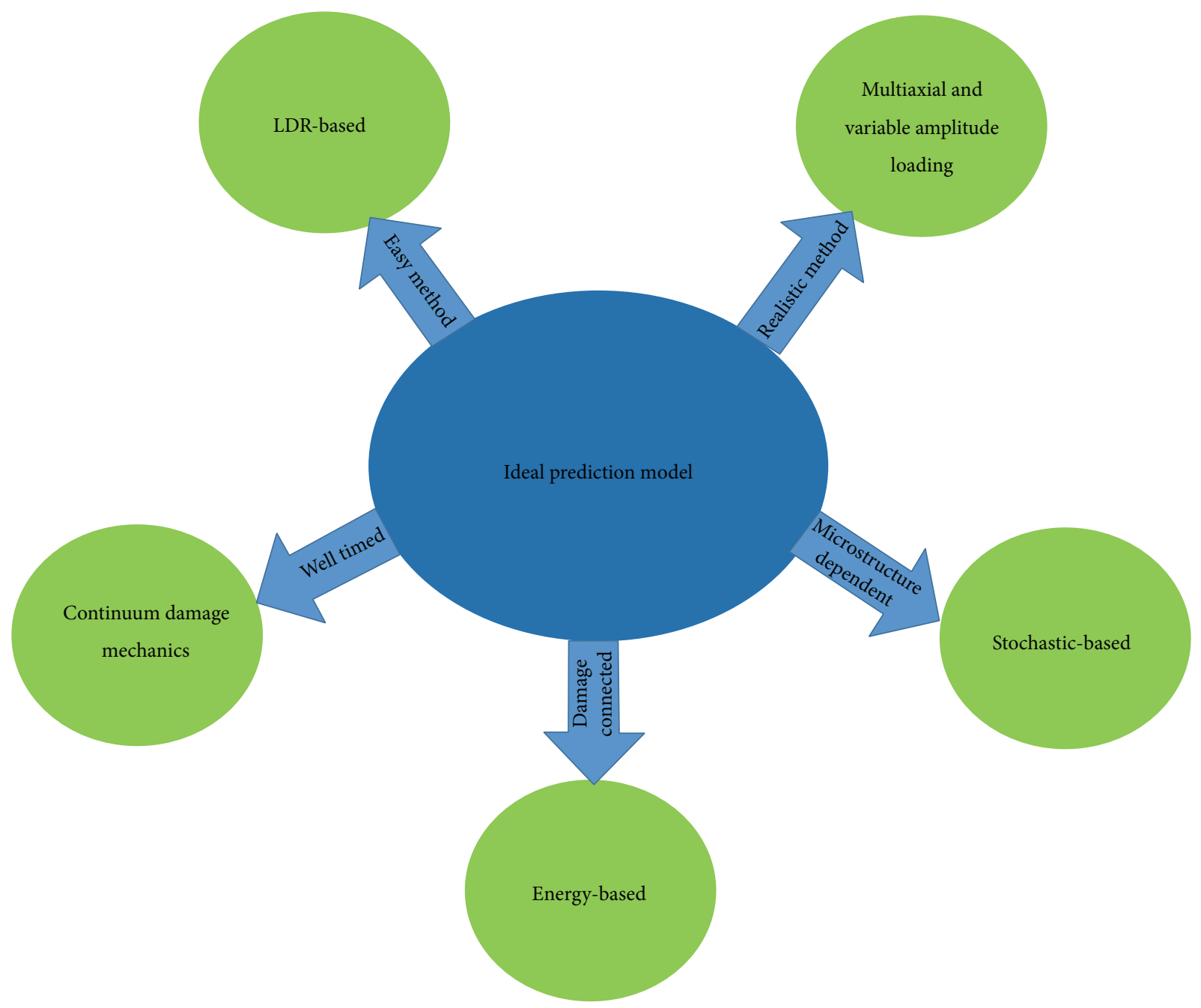

Figure 8: Features of an ideal fatigue life prediction model.

researchers can opt for multivariable models to be computed, or approaches easier to handle leading to a "safe-life" model. As reported in Figure 8, an ideal fatigue life prediction model should include the main features of those already established, and its implementation in simulation systems could help engineers and scientists in a number of applications.

\section{Competing Interests}

The authors declare that they have no competing interests.

\section{Acknowledgments}

This research was made possible by a NPRP award NPRP 5-423-2-167 from the Qatar National Research Fund (a member of the Qatar Foundation).

\section{References}

[1] R. I. Stephens, A. Fatemi, R. Stephens, and H. O. Fuchs, Metal Fatigue in Engineering, John Wiley \& Sons, New York, NY, USA, 2000.
[2] M. A. Miner, "Cumulative damage in fatigue," Journal of Applied Mechanics, vol. 12, pp. A159-A164, 1945.

[3] G. Ayoub, M. Naït-Abdelaziz, F. Zaïri, and J. M. Gloaguen, "Multiaxial fatigue life prediction of rubber-like materials using the continuum damage mechanics approach," Procedia Engineering, vol. 2, no. 1, pp. 985-993, 2010.

[4] S. Suresh, Fatigue of Materials, Cambridge University Press, Cambridge, UK, 1991.

[5] A. Palmgren, "Die lebensdauer von kugellagern," Zeitschrift des Vereins Deutscher Ingenieure, vol. 68, pp. 339-341, 1924.

[6] J. Schijve, Fatigue of Structures and Materials, Springer Science \& Business Media, 2001.

[7] H. F. S. G. Pereira, A. M. P. de Jesus, A. A. Fernandes, and A. S. Ribeiro, "Analysis of fatigue damage under block loading in a low carbon steel," Strain, vol. 44, no. 6, pp. 429-439, 2008.

[8] L. Xi and Z. Songlin, "Strengthening of transmission gear under low-amplitude loads," Materials Science and Engineering A, vol. 488, no. 1-2, pp. 55-63, 2008.

[9] X. Lu and S. L. Zheng, "Strengthening and damaging under lowamplitude loads below the fatigue limit," International Journal of Fatigue, vol. 31, no. 2, pp. 341-345, 2009. 
[10] L. Xi and Z. Songlin, "Changes in mechanical properties of vehicle components after strengthening under low-amplitude loads below the fatigue limit," Fatigue and Fracture of Engineering Materials and Structures, vol. 32, no. 10, pp. 847-855, 2009.

[11] S. Oller, O. Salomón, and E. Oñate, "A continuum mechanics model for mechanical fatigue analysis," Computational Materials Science, vol. 32, no. 2, pp. 175-195, 2005.

[12] E. Zalnezhad, A. A. D. Sarhan, and M. Hamdi, "Investigating the fretting fatigue life of thin film titanium nitride coated aerospace Al7075-T6 alloy," Materials Science and Engineering A, vol. 559, pp. 436-446, 2013.

[13] G. X. Cheng and A. Plumtree, "A fatigue damage accumulation model based on continuum damage mechanics and ductility exhaustion," International Journal of Fatigue, vol. 20, no. 7, pp. 495-501, 1998.

[14] D.-G. Shang and W.-X. Yao, "A nonlinear damage cumulative model for uniaxial fatigue," International Journal of Fatigue, vol. 21, no. 2, pp. 187-194, 1999.

[15] T. Svensson, "Cumulative fatigue damage taking the threshold into account," Fatigue \& Fracture of Engineering Materials \& Structures, vol. 25, no. 8-9, pp. 871-875, 2002.

[16] M. Jono, "Fatigue damage and crack growth under variable amplitude loading with reference to the counting methods of stress-strain ranges," International Journal of Fatigue, vol. 27, no. 8, pp. 1006-1015, 2005.

[17] E. Zalnezhad, A. A. D. M. Sarhan, and M. Hamdi, "Prediction of TiN coating adhesion strength on aerospace AL7075-T6 alloy using fuzzy rule based system," International Journal of Precision Engineering and Manufacturing, vol. 13, no. 8, pp. 1453-1459, 2012.

[18] D. Kreiser, S. X. Jia, J. J. Han, and M. Dhanasekar, "A nonlinear damage accumulation model for shakedown failure," International Journal of Fatigue, vol. 29, no. 8, pp. 1523-1530, 2007.

[19] M. Makkonen, "Predicting the total fatigue life in metals," International Journal of Fatigue, vol. 31, no. 7, pp. 1163-1175, 2009.

[20] G. H. Majzoobi, R. Hojjati, M. Nematian, E. Zalnejad, A. R. Ahmadkhani, and E. Hanifepoor, "A new device for fretting fatigue testing," Transactions of the Indian Institute of Metals, vol. 63, no. 2-3, pp. 493-497, 2010.

[21] S.-P. Zhu and H.-Z. Huang, "A generalized frequency separation-strain energy damage function model for low cycle fatigue-creep life prediction," Fatigue and Fracture of Engineering Materials and Structures, vol. 33, no. 4, pp. 227-237, 2010.

[22] P. Grammenoudis, D. Reckwerth, and C. Tsakmakis, "Continuum damage models based on energy equivalence: part Iisotropic material response," International Journal of Damage Mechanics, vol. 18, no. 1, pp. 31-63, 2009.

[23] P. Grammenoudis, D. Reckwerth, and C. Tsakmakis, "Continuum damage models based on energy equivalence: part IIanisotropic material response," International Journal of Damage Mechanics, vol. 18, no. 1, pp. 65-91, 2009.

[24] E. Rejovitzky and E. Altus, "On single damage variable models for fatigue," International Journal of Damage Mechanics, vol. 22, no. 2, pp. 268-284, 2013.

[25] S. S. Kulkarni, L. Sun, B. Moran, S. Krishnaswamy, and J. D. Achenbach, "A probabilistic method to predict fatigue crack initiation," International Journal of Fracture, vol. 137, no. 1, pp. 9-17, 2006.

[26] B. Bhattacharya and B. Ellingwood, "A new CDM-based approach to structural deterioration," International Journal of Solids and Structures, vol. 36, no. 12, pp. 1757-1779, 1999.
[27] B. Bhattacharya and B. Ellingwood, "A CDM analysis of stochastic ductile damage growth and reliability," Probabilistic Engineering Mechanics, vol. 14, no. 1-2, pp. 45-54, 1999.

[28] J. Lemaitre, A Course on Damage Mechanics, Springer, New York, NY, USA, 1992.

[29] J. Lemaitre, "Evaluation of dissipation and damage in metals under dynamic loading," in Proceedings of the International Conference on the Mechanical Behavior of Materials I (ICMI '71), Kyoto, Japan, August 1971.

[30] D. Krajcinovic and G. U. Fonseka, "The continuous damage theory of brittle materials," Journal of Applied Mechanics, vol. 48, pp. 809-824, 1981.

[31] S. Chandrakanth and P. C. Pandey, "An isotropic damage model for ductile material," Engineering Fracture Mechanics, vol. 50, no. 4, pp. 457-465, 1995.

[32] A. M. P. De Jesus, A. S. Ribeiro, and A. A. Fernandes, "Finite element modeling of fatigue damage using a continuum damage mechanics approach," Journal of Pressure Vessel Technology, vol. 127, no. 2, pp. 157-164, 2005.

[33] Y.-C. Xiao, S. Li, and Z. Gao, "A continuum damage mechanics model for high cycle fatigue," International Journal of Fatigue, vol. 20, no. 7, pp. 503-508, 1998.

[34] O. E. Scott-Emuakpor, H. Shen, T. George, and C. Cross, "An energy-based uniaxial fatigue life prediction method for commonly used gas turbine engine materials," Journal of Engineering for Gas Turbines and Power, vol. 130, no. 6, Article ID 062504, 2008.

[35] W. Cui, "A state-of-the-art review on fatigue life prediction methods for metal structures," Journal of Marine Science and Technology, vol. 7, no. 1, pp. 43-56, 2002.

[36] N. P. Inglis, "Hysteresis and fatigue of Wöhler rotating cantilever specimen," Metallurgist, vol. 3, pp. 23-27, 1927.

[37] R. Zuchowski, "Specific strain work as both failure criterion and material damage measure," Res Mechanica, vol. 27, no. 4, pp. 309-322, 1989.

[38] B. Budiansky and R. J. O'Connell, "Elastic moduli of a cracked solid," International Journal of Solids and Structures, vol. 12, no. 2, pp. 81-97, 1976.

[39] E. Zalnezhad, A. A. D. M. Sarhan, and M. Hamdi, "Surface hardness prediction of $\mathrm{CrN}$ thin film coating on AL7075-T6 alloy using fuzzy logic system," International Journal of Precision Engineering and Manufacturing, vol. 14, no. 3, pp. 467-473, 2013.

[40] E. Macha and C. M. Sonsino, "Energy criteria of multiaxial fatigue failure," Fatigue and Fracture of Engineering Materials and Structures, vol. 22, no. 12, pp. 1053-1070, 1999.

[41] J. D. Morrow, "Cyclic plastic strain energy and fatigue of metals," in Proceedings of the ASTM International Fraction, Damping, and Cyclic Plasticity, 1965.

[42] E. Zalnezhad, A. A. D. Sarhan, and M. Hamdi, "A fuzzy logic based model to predict surface hardness of thin film TiN coating on aerospace AL7075-T6 alloy," The International Journal of Advanced Manufacturing Technology, vol. 68, no. 1, pp. 415-423, 2013.

[43] Y.-N. Fan, H.-J. Shi, and K. Tokuda, "A generalized hysteresis energy method for fatigue and creep-fatigue life prediction of 316L(N)," Materials Science and Engineering: A, vol. 625, pp. 205-212, 2015.

[44] T. Letcher, M.-H. H. Shen, O. E. Scott-Emuakpor, T. George, and C. Cross, "An energy-based critical fatigue life prediction method for AL6061-T6," Fatigue and Fracture of Engineering Materials and Structures, vol. 35, no. 9, pp. 861-870, 2012. 
[45] O. Scott-Emuakpor, T. George, C. Cross, and M.-H. H. Shen, "Multi-axial fatigue-life prediction via a strain-energy method," AIAA Journal, vol. 48, no. 1, pp. 63-72, 2010.

[46] T. Ghidini and C. Dalle Donne, "Fatigue life predictions using fracture mechanics methods," Engineering Fracture Mechanics, vol. 76, no. 1, pp. 134-148, 2009.

[47] P. Paris and F. Erdogan, "A critical analysis of crack propagation laws," Journal of Basic Engineering, vol. 85, no. 4, pp. 528-533, 1963.

[48] R. P. Skelton, T. Vilhelmsen, and G. A. Webster, "Energy criteria and cumulative damage during fatigue crack growth," International Journal of Fatigue, vol. 20, no. 9, pp. 641-649, 1998.

[49] G. S. Wang, "An EPFM analysis of crack initiation, stable growth and instability," Engineering Fracture Mechanics, vol. 50, no. 2, pp. 261-282, 1995.

[50] J. R. Rice, "A path independent integral and the approximate analysis of strain concentration by notches and cracks," Journal of Applied Mechanics, vol. 35, no. 2, pp. 379-386, 1968.

[51] N. Pugno, M. Ciavarella, P. Cornetti, and A. Carpinteri, "A generalized Paris' law for fatigue crack growth," Journal of the Mechanics and Physics of Solids, vol. 54, no. 7, pp. 1333-1349, 2006.

[52] A. Wöhler, "Tests to determine the forces acting on railway wagon axles, and the capacity of resistance of the axles," $Z$ Bauw, vol. 10, pp. 583-616, 1860.

[53] N. Pugno, P. Cornetti, and A. Carpinteri, "New unified laws in fatigue: from the Wöhler's to the Paris' regime," Engineering Fracture Mechanics, vol. 74, no. 4, pp. 595-601, 2007.

[54] N. F. Mott, "A theory of the origin of fatigue cracks," Acta Metallurgica, vol. 6, no. 3, pp. 195-197, 1958.

[55] A. Hachim, H. Farid, M. El Ghorba, K. El Had, A. Akef, and M. Chergui, "Prediction and evolution of the fatigue crack initiation in S355 Steel by the probabilistic method," International Journal of Engineering Science, vol. 1, pp. 16-21, 2012.

[56] K. Tanaka and T. Mura, "A dislocation model for fatigue crack initiation," Journal of Applied Mechanics, vol. 48, no. 1, pp. 97103, 1981.

[57] R. Kapoor, V. S. H. Rao, R. S. Mishra, J. A. Baumann, and G. Grant, "Probabilistic fatigue life prediction model for alloys with defects: applied to A206," Acta Materialia, vol. 59, no. 9, pp. 3447-3462, 2011.

[58] K. Tanaka and T. Mura, "A theory of fatigue crack initiation at inclusions," Metallurgical Transactions A, vol. 13, no. 1, pp. 117$123,1982$.

[59] K. Dang-Van, "Macro-micro approach in high-cycle multiaxial fatigue," in Advances in Multiaxial Fatigue, ASTM, 1993.

[60] T. Mura and Y. Nakasone, "Theory of fatigue crack initiation in solids," Journal of Applied Mechanics, vol. 57, no. 1, pp. 1-6, 1990.

[61] K. S. Chan, "A microstructure-based fatigue-crack-initiation model," Metallurgical and Materials Transactions A, vol. 34, no. 1, pp. 43-58, 2003.

[62] G. Venkataraman, Y.-W. Chung, Y. Nakasone, and T. Mura, "Free energy formulation of fatigue crack initiation along persistent slip bands: calculation of S-N curves and crack depths," Acta Metallurgica et Materialia, vol. 38, no. 1, pp. 3140, 1990.

[63] G. Venkataraman, Y. W. Chung, and T. Mura, "Application of minimum energy formalism in a multiple slip band model for fatigue-I. Calculation of slip band spacings," Acta Metallurgica et Materialia, vol. 39, no. 11, pp. 2621-2629, 1991.
[64] G. Venkataraman, Y. W. Chung, and T. Mura, "Application of minimum energy formalism in a multiple slip band model for fatigue-II. Crack nucleation and derivation of a generalised Coffin-Manson law," Acta Metallurgica et Materialia, vol. 39, no. 11, pp. 2631-2638, 1991.

[65] K. S. Chan, "Scaling laws for fatigue crack," Metallurgical Transactions A, vol. 24, no. 11, pp. 2473-2486, 1993.

[66] K. S. Chan and T. Y. Torng, "A probabilistic treatment of microstructural effects on fatigue crack growth of large cracks," Journal of Engineering Materials and Technology, vol. 118, no. 3, pp. 379-386, 1996.

[67] K. S. Chan and M. P. Enright, "Probabilistic micromechanical modeling of fatigue-life variability in an $\alpha+\beta$ Ti alloy," Metallurgical and Materials Transactions A, vol. 36, no. 10, pp. 2621-2631, 2005.

[68] K. J. Miller, “The short crack problem," Fatigue \& Fracture of Engineering Materials \& Structures, vol. 5, no. 3, pp. 223-232, 1982.

[69] K. J. Miller, "The behavior of short fatigue cracks and their initiation: part II-a general summary," Fatigue \& Fracture of Engineering Materials \& Structures, vol. 10, no. 2, pp. 93-113, 1987.

[70] KJ. Miller, "Metal fatigue a new perspective," in Topics in Fracture and Fatigue, Springer, Berlin, Germany, 1992.

[71] K. J. Miller, "The behavior of short fatigue cracks and their initiations," in Mechanicanical Behavior of Materials- $V$, Pergamon Press, 1987.

[72] S. Suresh and R. O. Ritchie, "Propagation of short fatigue cracks," International Metals Reviews, vol. 29, pp. 445-476, 1984.

[73] M. Amiri and M. Modarres, "Short fatigue crack initiation and growth modeling in aluminum 7075-T6," Journal of Mechanical Engineering Science, vol. 229, no. 7, pp. 1206-1214, 2015.

[74] H. Ogi, M. Hirao, and S. Aoki, "Noncontact monitoring of surface-wave nonlinearity for predicting the remaining life of fatigued steels," Journal of Applied Physics, vol. 90, no. 1, pp. 438442, 2001.

[75] W. L. Morris, O. Buck, and R. V. Inman, "Acoustic harmonic generation due to fatigue damage in high-strength aluminum," Journal of Applied Physics, vol. 50, no. 11, pp. 6737-6741, 1979.

[76] A. Melander and M. Larsson, "The effect of stress amplitude on the cause of fatigue crack initiation in a spring steel," International Journal of Fatigue, vol. 15, no. 2, pp. 119-131, 1993.

[77] A. de Bussac and J. C. Lautridou, "A probabilistic model for prediction of LCF surface crack initiation in PM alloys," Fatigue \& Fracture of Engineering Materials \& Structures, vol. 16, no. 8, pp. 861-874, 1993.

[78] M. T. Todinov, "A probabilistic method for predicting fatigue life controlled by defects," Materials Science and Engineering A, vol. 255, no. 1-2, pp. 117-123, 1998.

[79] A. de Bussac, "Prediction of the competition between surface and internal fatigue crack initiation in PM alloys," Fatigue \& Fracture of Engineering Materials \& Structures, vol. 17, no. 11, pp. 1319-1325, 1994.

[80] A. Manonukul and F. P. E. Dunne, "High- and low-cycle fatigue crack initiation using polycrystal plasticity," Proceedings of the Royal Society of London A: Mathematical, Physical and Engineering Sciences, vol. 460, no. 2047, pp. 1881-1903, 2004.

[81] M. Makkonen, "Statistical size effect in the fatigue limit of steel," International Journal of Fatigue, vol. 23, no. 5, pp. 395-402, 2001.

[82] M. Makkonen, "Notch size effects in the fatigue limit of steel," International Journal of Fatigue, vol. 25, no. 1, pp. 17-26, 2002. 
[83] A. Pineau, "Superalloy discs durability and damage tolerance in relation to inclusions," in High Temperature Materials for Power Engineering, Part II, Kluwer Academic, New York, NY, USA, 1990.

[84] S. Deyber, F. Alexandre, J. Vaissaud, and A. Pineau, "Probabilistic life of DA718 for aircraft engine disks," in Superalloys 718, 625, 706 and Derivatives, E. A. Loria, Ed., pp. 97-110, The Minerals, Metals \& Materials Society, 2005.

[85] A. Pineau and S. D. Antolovich, "High temperature fatigue of nickel-base superalloys-a review with special emphasis on deformation modes and oxidation," Engineering Failure Analysis, vol. 16, no. 8, pp. 2668-2697, 2009.

[86] D. Taylor, "Geometrical effects in fatigue: a unifying theoretical model," International Journal of Fatigue, vol. 21, no. 5, pp. 413420, 2000.

[87] M. K. Chryssanthopoulos and T. D. Righiniotis, "Fatigue reliability of welded steel structures," Journal of Constructional Steel Research, vol. 62, no. 11, pp. 1199-1209, 2006.

[88] K. Tanaka and S. Matsuoka, "A tentative explanation for two parameters, C and $\mathrm{m}$, in Paris equation of fatigue crack growth," International Journal of Fracture, vol. 13, no. 5, pp. 563-583, 1977.

[89] K. Tanaka, "A correlation of $\Delta \mathrm{K}$ th-value with the exponent, $\mathrm{m}$, in the equation of fatigue crack growth for various steels," International Journal of Fracture, vol. 15, pp. 57-68, 1979.

[90] S. M. Marco and W. L. Starkey, "A concept of fatigue damage," Transactions of the ASME, vol. 76, pp. 627-632, 1954.

[91] M. T. Todinov, "Probability distribution of fatigue life controlled by defects," Computers and Structures, vol. 79, no. 3, pp. 313-318, 2001.

[92] S.-P. Zhu, H.-Z. Huang, and Z.-L. Wang, "Fatigue life estimation considering damaging and strengthening of low amplitude loads under different load sequences using fuzzy sets approach," International Journal of Damage Mechanics, vol. 20, no. 6, pp. 876-899, 2011.

[93] J. C. Newman Jr., "A crack-closure model for predicting fatigue crack growth under aircraft loading," in Method and Models for Predicting Fatigue Crack Growth under Random Loading, ASTM, 1983.

[94] B. F. Spencer Jr. and J. Tang, "Markov process model for fatigue crack growth," Journal of Engineering Mechanics, vol. 114, no. 12, pp. 2134-2157, 1989.

[95] B. F. Spencer Jr., J. Tang, and M. E. Artley, "Stochastic approach to modeling fatigue crack growth," AIAA journal, vol. 27, no. 11, pp. 1628-1635, 1989.

[96] A. Ray and S. Tangirala, "Stochastic modeling of fatigue crack dynamics for on-line failure prognostics," IEEE Transactions on Control Systems Technology, vol. 4, no. 4, pp. 443-451, 1996.

[97] V. V. Bolotin, Prediction of Service Life for Machines and Structures, ASME Press, 1989.

[98] S. S. Manson and G. R. Halford, "Practical implementation of the double linear damage rule and damage curve approach for treating cumulative fatigue damage," International Journal of Fracture, vol. 17, no. 2, pp. 169-192, 1981.

[99] T. D. Righiniotis and M. K. Chryssanthopoulos, "Probabilistic fatigue analysis under constant amplitude loading," Journal of Constructional Steel Research, vol. 59, no. 7, pp. 867-886, 2003.

[100] BSI, "Guide on methods for assessing the acceptability of flaws in fusion welded structures," BS 7910, 2000.

[101] A. H. Jazwinski, Stochastic Processes and Filtering Theory, Courier Corporation, 2007.
[102] J. Maljaars, H. M. G. M. Steenbergen, and A. C. W. M. Vrouwenvelder, "Probabilistic model for fatigue crack growth and fracture of welded joints in civil engineering structures," International Journal of Fatigue, vol. 38, pp. 108-117, 2012.

[103] H. Ishikawa, A. Tsurui, H. Tanaka, and H. Ishikawa, "Reliability assessment of structures based upon probabilistic fracture mechanics," Probabilistic Engineering Mechanics, vol. 8, no. 1, pp. 43-56, 1993.

[104] N. Yazdani and P. Albrecht, "Probabilistic fracture mechanics application to highway bridges," Engineering Fracture Mechanics, vol. 37, no. 5, pp. 969-985, 1990.

[105] M. Lukić and C. Cremona, "Probabilistic assessment of welded joints versus fatigue and fracture," Journal of Structural Engineering, vol. 127, no. 2, pp. 211-218, 2001.

[106] J. C. Ting and F. V. Lawrence, "Modeling the long-life fatigue behavior of a cast aluminum alloy," Fatigue \& Fracture of Engineering Materials and Structures, vol. 16, no. 6, pp. 631-647, 1993.

[107] A. Ray, "Stochastic modeling of fatigue crack damage for risk analysis and remaining life prediction," Journal of Dynamic Systems, Measurement, and Control ASME, vol. 121, no. 3, pp. 386-393, 1999.

[108] M. M. Shokrieh and L. B. Lessard, "Progressive fatigue damage modeling of composite materials, part I: modeling," Journal of Composite Materials, vol. 34, no. 13, pp. 1056-1080, 2000.

[109] X. Diao, L. B. Lessard, and M. M. Shokrieh, "Statistical model for multiaxial fatigue behavior of unidirectional plies," Composites Science and Technology, vol. 59, no. 13, pp. 2025-2035, 1999.

[110] S. Baradaran, W. J. Basirun, E. Zalnezhad, M. Hamdi, A. A. D. Sarhan, and Y. Alias, "Fabrication and deformation behaviour of multilayer $\mathrm{Al}_{2} \mathrm{O}_{3} / \mathrm{Ti} / \mathrm{TiO}_{2}$ nanotube arrays," Journal of the Mechanical Behavior of Biomedical Materials, vol. 20, pp. 272282, 2013.

[111] Z. Hashin, "Failure criteria for unidirectional fiber composites," Journal of Applied Mechanics, vol. 47, pp. 324-334, 1980.

[112] F. E. Richart and N. M. Newmark, "A hypothesis for the determination of cumulative damage in fatigue," Proceedings of the American Society for Testing Materials, vol. 48, pp. 767-800, 1948.

[113] H. T. Corten and T. J. Dolan, "Cumulative fatigue damage," in Proceedings of the International Conference on Fatigue of Metals, Institution of Mechanical Engineering and American Society of Mechanical Engineers, 1956.

[114] A. M. Freudenthal and R. A. Heller, "On stress interaction in fatigue and a cumulative damage rule," Journal of the Aerospace Sciences, vol. 26, no. 7, pp. 431-442, 1959.

[115] A. A. D. Sarhan, E. Zalnezhad, and M. Hamdi, "The influence of higher surface hardness on fretting fatigue life of hard anodized aerospace AL7075-T6 alloy," Materials Science and Engineering A, vol. 1, pp. 23-40, 2012.

[116] R. Spitzer and H. T. Corten, "Effect of loading sequence on cumulative fatigue damage of 7071-T6 aluminum alloy," Proceedings ASTM, vol. 61, pp. 679-703, 1961.

[117] R. Badaliance, "Fatigue life prediction: metals and composites," in Fracture Mechanics Methodology, Martinus Nijhoff, 1984.

[118] S. S. Manson, A. J. Nachtigall, C. R. Ensign, and J. C. Freche, "Further investigation of a relation for cumulative fatigue damage in bending," Journal of Engineering for Industry, vol. 87, no. 1, pp. 25-35, 1965.

[119] Z. Marciniak, D. Rozumek, and E. Macha, "Fatigue lives of 18G2A and 10HNAP steels under variable amplitude and 
random non-proportional bending with torsion loading," International Journal of Fatigue, vol. 30, no. 5, pp. 800-813, 2008.

[120] E. Zalnezhad, A. A. D. Sarhan, and M. Hamdi, "A fuzzy logic based model to predict surface hardness of thin film TiN coating on aerospace AL7075-T6 alloy," International Journal of Advanced Manufacturing Technology, vol. 68, no. 1, pp. 415-423, 2013.

[121] H. Gao, H.-Z. Huang, Z. Lv, F.-J. Zuo, and H.-K. Wang, "An improved Corten-Dolan's model based on damage and stress state effects," Journal of Mechanical Science and Technology, vol. 29, no. 8, pp. 3215-3223, 2015.

[122] S.-P. Zhu, H.-Z. Huang, Y. Liu, L.-P. He, and Q. Liao, "A practical method for determining the Corten-Dolan exponent and its application to fatigue life prediction," International Journal of Turbo and Jet Engines, vol. 29, no. 2, pp. 79-87, 2012.

[123] T. Nicholas, High Cycle Fatigue: A Mechanics of Materials Perspective, Elsevier, 2006.

[124] H. J. Grover, "An observation concerning the cycle ratio in cumulative damage," in Proceedings of the ASTM Symposium on Fatigue Aircraft Structures, January 1960.

[125] S. S. Manson, "Interfaces between fatigue, creep, and fracture," International Journal of Fracture Mechanics, vol. 2, no. 1, pp. 328363, 1966.

[126] S. S. Manson and G. R. Halford, "Re-examination of cumulative fatigue damage analysis-an engineering perspective," Engineering Fracture Mechanics, vol. 25, no. 5-6, pp. 539-571, 1986.

[127] S. S. Zhao-Feng, W. De-Jun, and X. Hao, “Two-stage fatigue damage cumulative rule," International Journal of Fatigue, vol. 14, no. 6, pp. 395-398, 1992.

[128] S. S. Manson and G. R. Halford, "Complexities of hightemperature metal fatigue: some steps toward understanding," Israel Journal of Technology, vol. 21, pp. 29-53, 1983.

[129] M. A. McGaw, Cumulative Fatigue Damage Models, NASA Lewis Structures Technology, 1988.

[130] D. L. Henry, "A theory of fatigue damage accumulation in steel," ASME Transactions, vol. 77, pp. 913-918, 1955.

[131] R. R. Gatts, "Application of a cumulative damage concept to fatigue," Journal of Basic Engineering T, vol. 83, pp. 529-540, 1961.

[132] F. R. Shanley, "A theory of fatigue based on unbonding during reversed slip," Report P-350, The Rand Corporation, 1952.

[133] S. R. Valluri, "A unified engineering theory of high stress level fatigue," Tech. Rep. ARL-181, 1961.

[134] T. Bui-Quoc, "An interaction effect consideration in cumulative damage on a mild steel under torsion loading," in Proceedings of the 5th International Conference on Fracture, vol. 5, pp. 26252633, Cannes, France, 1982.

[135] T. Bui-Quoc, J. Dubuc, A. Bazergui, and A. Biron, "Cumulative fatigue damage under strain controlled conditions," Journal of Materials, vol. 3, pp. 718-737, 1971.

[136] J. Dubuc, T. Bui-Quoc, A. Barzegui, and A. Biron, "Unified theory of cumulative damage in metal fatigue," W.R.C. Bulletin, vol. 162, pp. 1-20, 1971.

[137] T. Bui-Quoc, J. A. Choquet, and A. Biron, "Cumulative fatigue damage on large steel specimens under axial programmed loading with nonzero mean stress," Journal of Engineering Materials and Technology ASME, vol. 98, no. 3, pp. 249-255, 1976.

[138] T. Bui-Quoc, "Cumulative damage with interaction effect due to fatigue under torsion loading - an analysis of the interaction effect on the basis of a continuous-damage concept is made using published test results obtained from two-step fatigue tests at room temperature," Experimental Mechanics, vol. 22, no. 5, pp. 180-187, 1982.

[139] T. Bui-Quoc, "A simplified model for cumulative damage with interaction effects," in Proceedings of the Joint Conference on Experimental Mechanics, Society for Experimental Stress Analysis, May 1982.

[140] A. Biron and T. Bui-Quoc, "Cumulative damage concepts with interaction effect consideration for fatigue or creep; a perspective," in Proceedings of the Transactions of the 6th International Conference on Structural Mechanical Reaction Technology, Paris, France, 1981.

[141] M. Bernard-Connolly, T. Bui-Quoc, and A. Biron, "Multilevel strain controlled fatigue on a type 304 stainless steel," Journal of Engineering Materials and Technology ASME, vol. 105, no. 3, pp. 188-194, 1983.

[142] T. Bui-Quoc, "High-temperature fatigue-life estimation: extension of a unified theory," Experimental Mechanics, vol. 15, no. 6, pp. 219-225, 1975.

[143] A. Zhang, T. Bui-Quoc, and R. Gomuc, "A procedure for low cycle fatigue life prediction for various temperatures and strain rates," Journal of Engineering Materials and Technology, Transactions of the ASME, vol. 112, no. 4, pp. 422-428, 1990.

[144] T. Bui-Qoc, "An engineering approach for cumulative damage in metals under creep loading," Journal of Engineering Materials and Technology, vol. 101, no. 4, pp. 337-343, 1979.

[145] T. Bui-Quoc and A. Biron, "Cumulative damage with interaction effect due to creep on a Cr-Mo-V steel," in Proceedings of the International Conference on Engineering Aspects of Creep, 1980.

[146] T. Bui-Quoc and A. Biron, "Interaction effect consideration in cumulative damage in metals due to creep," Journal of Mechanical Engineering Science, vol. 23, no. 6, pp. 281-288, 1981.

[147] T. Bui-Quoc, "Recent developments of continuous damage approaches for the analysis of material behavior under creepfatigue loading," Tech. Rep. CONF-820601, Section of Applied Mechanics, 1982.

[148] E. Zalnezhad, S. Baradaran, A. R. Bushroa, and A. A. D. Sarhan, "Mechanical property enhancement of Ti- $6 \mathrm{Al}-4 \mathrm{~V}$ by multilayer thin solid film $\mathrm{Ti} / \mathrm{TiO}_{2}$ nanotubular array coating for biomedical application," Metallurgical and Materials Transactions A, vol. 45, no. 2, pp. 785-797, 2014.

[149] R. Gomuc, T. Bui-Quoc, and A. Biron, "Evaluation of the creep fatigue behavior of $2.25 \mathrm{Cr}-1 \mathrm{Mo}$ steel by a continuous damage approach," Res Mechanica, vol. 21, pp. 135-154, 1987.

[150] R. Gomuc, T. Bui-Quoc, A. Biron, and M. Bernard, "Analysis of type 316 stainless steel behavior under fatigue, creep and combined fatigue-creep loading," Journal of Pressure Vessel Technology, vol. 112, no. 3, pp. 240-250, 1990.

[151] Z. Hashin and A. Rotem, "A cumulative damage theory of fatigue failure," Materials Science and Engineering, vol. 34, no. 2, pp. 147-160, 1978.

[152] M. Ben-Amoz, "A cumulative damage theory for fatigue life prediction," Engineering Fracture Mechanics, vol. 37, no. 2, pp. 341-347, 1990.

[153] S. Subramanyan, "A cumulative damage rule based on the knee point of the S-N curve," Journal of Engineering Materials and Technology, vol. 98, no. 4, pp. 316-321, 1976.

[154] H. H. E. Leipholz, "On the modified S-N curve for metal fatigue prediction and its experimental verification," Engineering Fracture Mechanics, vol. 23, no. 3, pp. 495-505, 1986. 
[155] H. Gao, H.-Z. Huang, S.-P. Zhu, Y.-F. Li, and R. Yuan, "A modified nonlinear damage accumulation model for fatigue life prediction considering load interaction effects," The Scientific World Journal, vol. 2014, Article ID 164378, 7 pages, 2014.

[156] P. J. Huffman and S. P. Beckman, "A non-linear damage accumulation fatigue model for predicting strain life at variable amplitude loadings based on constant amplitude fatigue data," International Journal of Fatigue, vol. 48, pp. 165-169, 2013.

[157] R. Yuan, H. Li, H.-Z. Huang, S.-P. Zhu, and H. Gao, "A nonlinear fatigue damage accumulation model considering strength degradation and its applications to fatigue reliability analysis," International Journal of Damage Mechanics, vol. 24, no. 5, pp. 646-662, 2015.

[158] Z. Lv, H.-Z. Huang, S.-P. Zhu, H. Gao, and F. Zuo, "A modified nonlinear fatigue damage accumulation model," International Journal of Damage Mechanics, vol. 24, no. 2, pp. 168-181, 2014.

[159] C. Sun, J. Xie, A. Zhao, Z. Lei, and Y. Hong, "A cumulative damage model for fatigue life estimation of high-strength steels in high-cycle and very-high-cycle fatigue regimes," Fatigue \& Fracture of Engineering Materials \& Structures, vol. 35, no. 7, pp. 638-647, 2012.

[160] A. Aïd, A. Amrouche, B. B. Bouiadjra, M. Benguediab, and G. Mesmacque, "Fatigue life prediction under variable loading based on a new damage model," Materials and Design, vol. 32, no. 1, pp. 183-191, 2011.

[161] C. Bathias, "There is no infinite fatigue life in metallic materials," Fatigue \& Fracture of Engineering Materials \& Structures, vol. 22, no. 7, pp. 559-565, 1999.

[162] O. H. Basquin, "The exponential law of endurance tests," Proceedings of the American Society for Testing and Materials, vol. 10, pp. 625-630, 1910.

[163] F. Kun, H. A. Carmona, J. S. Andrade Jr., and H. J. Herrmann, "Universality behind basquin's law of fatigue," Physical Review Letters, vol. 100, no. 9, Article ID 094301, 4 pages, 2008.

[164] E. Gassner, "Betriebsfestigkeit, eine Bemessungsgrundlage für Konstruktionsteile mit statistisch wechselnden Betriebsbeanspruchungen," Konstruktion, vol. 6, pp. 97-104, 1954.

[165] K. E. Olsson, "Fatigue reliability prediction," Scandinavian Journal of Metallurgy, vol. 18, no. 4, pp. 176-180, 1989.

[166] W. Schütz, "The significance of service load data for fatigue life analysis," in Fatigue Design ESIS16. MEP, 1993.

[167] W. Schütz and P. Heuler, "Miner's rule revisited," in Proceedings of the AGARD-SMP Meeting, Industrinlagen-Betriebsgesellshaft GmbH, Ottobrunn, Germany, 1993.

[168] P. C. McKeighan and N. Ranganathan, Fatigue Testing and Analysis Under Variable Amplitude Loading Conditions, ASTM International, West Conshohocken, Pa, USA, 1995.

[169] D. Rial, H. Kebir, E. Wintrebert, and J.-M. Roelandt, "Multiaxial fatigue analysis of a metal flexible pipe," Materials and Design, vol. 54, pp. 796-804, 2014.

[170] M. Skorupa, "Load interaction effects during fatigue crack growth under variable amplitude loading-a literature review. Part I: empirical trends," Fatigue \& Fracture of Engineering Materials \& Structures, vol. 21, no. 8, pp. 987-1006, 1998.

[171] M. Skorupa, "Load interaction effects during fatigue crack growth under variable amplitude loading-a literature review. Part II: qualitative interpretation," Fatigue \& Fracture of Engineering Materials \& Structures, vol. 22, no. 10, pp. 905-926, 1999.

[172] Y. Liu and S. Mahadevan, "Stochastic fatigue damage modeling under variable amplitude loading," International Journal of Fatigue, vol. 29, no. 6, pp. 1149-1161, 2007.
[173] L. Jarfall, "Prediction of fatigue life and crack growth using spectrum test data," SAAB-SCANIA Report TKH R-3379, 1985.

[174] P. Johannesson, T. Svensson, and J. de Maré, "Fatigue life prediction based on variable amplitude tests-methodology," International Journal of Fatigue, vol. 27, no. 8, pp. 954-965, 2005.

[175] J. W. Harris and H. Stocker, "Maximum likelihood method," in Handbook of Mathematics and Computational Science, Springer, New York, NY, USA, 1998.

[176] J. Colin and A. Fatemi, "Variable amplitude cyclic deformation and fatigue behaviour of stainless steel 304L including step, periodic, and random loadings," Fatigue and Fracture of Engineering Materials and Structures, vol. 33, no. 4, pp. 205-220, 2010.

[177] S. Kumai and Y. Higo, "Effects of delamination on fatigue crack growth retardation after single tensile overloads in $8090 \mathrm{Al}-\mathrm{Li}$ alloys," Materials Science and Engineering: A, vol. 221, no. 1-2, pp. 154-162, 1996.

[178] V. Zitounis and P. E. Irving, "Fatigue crack acceleration effects during tensile underloads in 7010 and 8090 aluminium alloys," International Journal of Fatigue, vol. 29, no. 1, pp. 108-118, 2007.

[179] O. E. Wheeler, "Spectrum loading and crack growth," Journal of Basic Engineering, Transactions of the ASME, vol. 94, no. 1, pp. 181-186, 1972.

[180] J. Willenborg, R. M. Engle, and H. A. Wood, "A crack growth retardation model using an effective stress concept," Tech. Rep. AFFDL TM-71-1-FBR, 1971.

[181] W. Elber, "Fatigue crack closure under cyclic tension," Engineering Fracture Mechanics, vol. 2, no. 1, pp. 37-45, 1970.

[182] R. O. Ritchie, S. Suresh, and C. M. Moses, "Near-threshold fatigue crack growth in 21/4 Cr-1Mo pressure vessel steel in air and hydrogen," Journal of Engineering Materials and Technology, vol. 102, no. 3, pp. 293-299, 1980.

[183] R. O. Ritchie and S. Suresh, "Some considerations on fatigue crack closure at near-threshold stress intensities due to fracture surface morphology," Metallurgical Transactions A, vol. 13, no. 5, pp. 937-940, 1982.

[184] S. Kwofie and N. Rahbar, "A fatigue driving stress approach to damage and life prediction under variable amplitude loading," International Journal of Damage Mechanics, vol. 22, no. 3, pp. 393-404, 2013.

[185] S. Kwofie and N. Rahbar, "An equivalent driving force model for crack growth prediction under different stress ratios," International Journal of Fatigue, vol. 33, no. 9, pp. 1199-1204, 2011.

[186] F.-J. Zuo, H.-Z. Huang, S.-P. Zhu, Z. Lv, and H. Gao, "Fatigue life prediction under variable amplitude loading using a non-linear damage accumulation model," International Journal of Damage Mechanics, vol. 24, no. 5, pp. 767-784, 2015.

[187] S. Benkabouche, H. Guechichi, A. Amrouche, and M. Benkhettab, "A modified nonlinear fatigue damage accumulation model under multiaxial variable amplitude loading," International Journal of Mechanical Sciences, vol. 100, pp. 180-194, 2015.

[188] D. L. McDowell and R. Ellis, Advances in Multiaxial Fatigue, ASTM International, West Conshohocken, Pa, USA, 1993.

[189] C. H. Wang and M. W. Brown, "Life prediction techniques for variable amplitude multiaxial fatigue-part 1: theories," Journal of Engineering Materials and Technology, vol. 118, no. 3, pp. 367370, 1996.

[190] A. Fatemi and N. Shamsaei, "Multiaxial fatigue: an overview and some approximation models for life estimation," International Journal of Fatigue, vol. 33, no. 8, pp. 948-958, 2011. 
[191] J. A. Bannantine and D. F. Socie, "A variable amplitude multiaxial fatigue life prediction method," in Proceedings of the 3rd International Conference on Biaxial/Multiaxial Fatigue, Stuttgart, Germany, April 1989.

[192] C. H. Wang and M. W. Brown, "A study of the deformation behaviour under multiaxial loading," European Journal of Mechanics A-Solids, vol. 13, pp. 175-188, 1994.

[193] D. Socie, "A summary and interpretation of the society of automotive engineers biaxial testing program," in Multiaxial Fatigue: Analysis and Experiments, Society of Automotive Engineers Inc, 1989.

[194] S. Goudarzi, K. Khojier, H. Savaloni, and E. Zalnezhad, "On the dependence of mechanical and tribological properties of sputtered chromium nitride thin films on deposition power," Advanced Materials Research, vol. 829, pp. 352-356, 2014.

[195] M. W. Brown and K. J. Miller, "A theory for fatigue under multiaxial stress-strain conditions," Proceedings of the Institution of Mechanical Engineers, vol. 187, pp. 745-755, 1973.

[196] E. Krempl, "The influence of state stress on low-cycle fatigue of structural materials," ASTM STP, 1974.

[197] Y. S. Garud, "Multiaxial fatigue: a survey of the state of the art," Journal of Testing and Evaluation, vol. 9, no. 3, pp. 165-178, 1981.

[198] E. Zalnezhad, A. A. D. Sarhan, and M. Hamdi, "Fretting fatigue life evaluation of multilayer $\mathrm{Cr}$-CrN-coated Al7075-T6 with higher adhesion strength-fuzzy logic approach," International Journal of Advanced Manufacturing Technology, vol. 69, no. 5-8, pp. 1153-1164, 2013.

[199] M. De Freitas, B. Li, and J. L. T. Santos, "A numerical approach for high-cycle fatigue life prediction with multiaxial loading," in Multiaxial Fatigue and Deformation: Testing and Prediction, ASTM, 2000.

[200] J. A. Bannantine and D. F. Socie, Multiaxial Fatigue Life Estimation Techniques, Advances in Fatigue Life Prediction Techniques, ASTM, 1992.

[201] M. Mitchell and L. Landgraf, Advances in Fatigue Lifetime Predictive Techniques, ASTM, 1992.

[202] S. Kalluri and J. P. Bonacuse, Multiaxial Fatigue and Deformation: Testing and Prediction, ASTM International, West Conshohocken, Pa, USA, 2000.

[203] C. A. Gonçalves, J. A. Araújo, and E. N. Mamiya, "Multiaxial fatigue: a stress based criterion for hard metals," International Journal of Fatigue, vol. 27, no. 2, pp. 177-187, 2005.

[204] E. Zalnezhad, A. A. D. Sarhan, and M. Hamdi, "Investigating the effects of hard anodizing parameters on surface hardness of hard anodized aerospace AL7075-T6 alloy using fuzzy logic approach for fretting fatigue application," International Journal of Advanced Manufacturing Technology, vol. 68, no. 1-4, pp. 453464, 2013.

[205] I. V. Papadopoulos, P. Davoli, C. Gorla, M. Filippini, and A. Bernasconi, "A comparative study of multiaxial high-cycle fatigue criteria for metals," International Journal of Fatigue, vol. 19, no. 3, pp. 219-235, 1997.

[206] A. Carpinteri and A. Spagnoli, "Multiaxial high-cycle fatigue criterion for hard metals," International Journal of Fatigue, vol. 23, no. 2, pp. 135-145, 2001.

[207] G. Q. Sun, D. Wang, and D. G. Shang, "Time-dependent multiaxial fatigue and life prediction for nickel-based GH4169 alloy," Fatigue and Fracture of Engineering Materials and Structures, vol. 36, no. 10, pp. 1039-1050, 2013.

[208] Y. Liu and S. Mahadevan, "Multiaxial high-cycle fatigue criterion and life prediction for metals," International Journal of Fatigue, vol. 27, no. 7, pp. 790-800, 2005.
[209] H. J. Gough and H. V. Pollard, "The strength of metals under combined alternating stress," Proceedings of the Institution of Mechanical Engineers, vol. 131, pp. 3-18, 1935.

[210] H. J. Gough, H. V. Pollard, and W. J. Clenshaw, Some Experiments on the Resistance of Metals to Fatigue Under Combined Stresses, vol. 2522 of Aeronautical Research Council Reports, 1951.

[211] H. Kakuno and Y. Kawada, "A new criterion of fatigue strength of a round bar subjected to combined static and repeated bending and torsion," Fatigue \& Fracture of Engineering Materials and Structures, vol. 2, no. 2, pp. 229-236, 1979.

[212] E. Zalnezhad, A. A. D. Sarhan, and P. Jahanshahi, "A new fretting fatigue testing machine design, utilizing rotating-bending principle approach," The International Journal of Advanced Manufacturing Technology, vol. 70, no. 9-12, pp. 2211-2219, 2014.

[213] Y.-Y. Wang and W.-X. Yao, "Evaluation and comparison of several multiaxial fatigue criteria," International Journal of Fatigue, vol. 26, no. 1, pp. 17-25, 2004.

[214] A. Fatemi and P. Kurath, "Multiaxial fatigue life predictions under the influence of mean-stresses," Journal of Engineering Materials and Technology, vol. 110, no. 4, pp. 380-388, 1988.

[215] W. F. Findley, "Modified theory of fatigue under combined stress," Proceedings of the Society for Experimental Stress Analysis, vol. 14, pp. 35-46, 1956.

[216] N. Shamsaei and A. Fatemi, "Effect of hardness on multiaxial fatigue behaviour and some simple approximations for steels," Fatigue \& Fracture of Engineering Materials \& Structures, vol. 32, no. 8, pp. 631-646, 2009.

[217] W. N. Findley, J. J. Coleman, and B. C. Hanley, "Theory fro combined bending and torsion fatigue with data for SAE 4340 steel," in Proceedings of the International Conference on Fatigue of Metals, Institute of Mechanical Engineers, London, UK, September 1956.

[218] D. L. McDiarmid, "A shear stress based critical plane criterion of multiaxial fatigue failure for design and life prediction," Fatigue \& Fracture of Engineering Materials \& Structures, vol. 17, pp. 1475-1485, 1994.

[219] R. N. Smith, P. P. Watson, and T. H. Topper, "A stress-strain parameter for the fatigue of metals," Journal of Materials Chemistry, vol. 5, pp. 767-778, 1970.

[220] M. Filippini, S. Foletti, and G. Pasquero, "Assessment of multiaxial fatigue life prediction methodologies for Inconel 718," Procedia Engineering, vol. 2, no. 1, pp. 2347-2356, 2010.

[221] G. Sines and J. L. Waisman, Metal Fatigue, McGraw-Hill, New York, NY, USA, 1959.

[222] B. Crossland, "Effect of large hydrostatic pressures on the torsional fatigue strength of an alloy steel," in Proceedings of the International Conference on Fatigue of Metals, London, UK, 1956.

[223] A. Carpinteri, M. De Freitas, and A. Spagnoli, Biaxial/Multiaxial Fatigue and Fracture, Elsevier, 2003.

[224] M. L. Roessle and A. Fatemi, "Strain-controlled fatigue properties of steels and some simple approximations," International Journal of Fatigue, vol. 22, no. 6, pp. 495-511, 2000.

[225] A. Carpinteri, A. Spagnoli, and S. Vantadori, "Multiaxial fatigue life estimation in welded joints using the critical plane approach," International Journal of Fatigue, vol. 31, no. 1, pp. 188196, 2009.

[226] A. Carpinteri, A. Spagnoli, and S. Vantadori, "Multiaxial fatigue assessment using a simplified critical plane-based criterion," International Journal of Fatigue, vol. 33, no. 8, pp. 969-976, 2011. 
[227] A. Carpinteri, C. Ronchei, A. Spagnoli, and S. Vantadori, "On the use of the Prismatic Hull method in a critical plane-based multiaxial fatigue criterion," International Journal of Fatigue, vol. 68, pp. 159-167, 2014.

[228] I. V. Papadopoulos, "Long life fatigue under multiaxial loading," International Journal of Fatigue, vol. 23, no. 10, pp. 839-849, 2001.

[229] J. L. Robert, "Fatigue life prediction under periodical or random multiaxial stress states," in Automation in Fatigue and Fracture: Testing and Analysis, ASTM, 1994.

[230] F. Morel, "Critical plane approach for life prediction of high cycle fatigue under multiaxial variable amplitude loading," International Journal of Fatigue, vol. 22, no. 2, pp. 101-119, 2000.

[231] Y. Liu and S. Mahadevan, "A unified multiaxial fatigue damage model for isotropic and anisotropic materials," International Journal of Fatigue, vol. 29, no. 2, pp. 347-359, 2007.

[232] Y. Murakami, The Rainflow Method in Fatigue: The Tatsuo Endo Memorial Volume, Butterworth-Heinemann, 1992.

[233] C. H. Wang and M. W. Brown, "A path-independent parameter for fatigue under proportional and non-proportional loading," Fatigue \& Fracture of Engineering Materials \& Structures, vol. 16, no. 12, pp. 1285-1298, 1993.

[234] D. Skibicki, Phenomena and Computational Models of NonProportional Fatigue of Materials, Springer, 2014.

[235] K. J. Miller, "Materials science perspective of metal fatigue resistance," Materials Science and Technology, vol. 9, no. 6, pp. 453-462, 1993.

[236] D. F. Socie and G. B. Marquis, Multiaxial Fatigue, Society of Automotive Engineers, 2000.

[237] N. Shamsaei, M. Gladskyi, K. Panasovskyi, S. Shukaev, and A. Fatemi, "Multiaxial fatigue of titanium including step loading and load path alteration and sequence effects," International Journal of Fatigue, vol. 32, no. 11, pp. 1862-1874, 2010.

[238] A. Aid, M. Bendouba, L. Aminallah, A. Amrouche, N. Benseddiq, and M. Benguediab, "An equivalent stress process for fatigue life estimation under multiaxial loadings based on a new non linear damage model," Materials Science and Engineering: A, vol. 538, pp. 20-27, 2012.

[239] G. Mesmacque, S. Garcia, A. Amrouche, and C. RubioGonzalez, "Sequential law in multiaxial fatigue, a new damage indicator," International Journal of Fatigue, vol. 27, no. 4, pp. 461467, 2005.

[240] S. Garcia, A. Amrouche, G. Mesmacque, X. Decoopman, and C. Rubio, "Fatigue damage accumulation of cold expanded hole in aluminum alloys subjected to block loading," International Journal of Fatigue, vol. 27, no. 10-12, pp. 1347-1353, 2005.

[241] A. Aid, J. Chalet, A. Amrouche, and G. Mesmacque, "A new damage indicator: from blocks loading to random loading," in Proceedings of the Fatigue Design Conference, Paris, France, November 2005.

[242] A. Ince and G. Glinka, "A generalized fatigue damage parameter for multiaxial fatigue life prediction under proportional and non-proportional loadings," International Journal of Fatigue, vol. 62 , pp. 34-41, 2014.

[243] C. Wang, D.-G. Shang, X.-W. Wang, H. Chen, and J.-Z. Liu, "Comparison of HCF life prediction methods based on different critical planes under multiaxial variable amplitude loading," Fatigue \& Fracture of Engineering Materials \& Structures, vol. 38, no. 4, pp. 392-401, 2015.

[244] F. Ellyin and D. Kujawski, "An energy-based fatigue failure criterion," in Microstructure and Mechanical Behaviour of Materials, EAMS, 1986.
[245] K. Golos and F. Ellyin, "Generalization of cumulative damage criterion to multilevel cyclic loading," Theoretical and Applied Fracture Mechanics, vol. 7, no. 3, pp. 169-176, 1987.

[246] G. Masing, "Eigenspannungen und verfestigung beim messing (Self stretching and hardening for brass)," in Proceedings of the 2nd International Congress for Applied Mechanics, Zürich, Switzerland, 1926.

[247] K. Golos and F. Ellyin, "Total strain energy density as a fatigue damage parameter," in Advances in Fatigue Science and Technology, vol. 159 of NATO ASI Series, pp. 849-858, Springer, Berlin, Germany, 1989.

[248] N. Xiaode, L. Guangxia, and L. Hao, "Hardening law and fatigue damage of a cyclic hardening metal," Engineering Fracture Mechanics, vol. 26, no. 2, pp. 163-170, 1987.

[249] B. N. Leis, "A nonlinear history-dependent damage model for low cycle fatigue," in Low Cycle Fatigue, ASTM, 1988.

[250] V. M. Radhakrishnan, "Cumulative damage in low-cycle fatigue," Experimental Mechanics, vol. 18, no. 8, pp. 292-296, 1978.

[251] V. M. Radhakrishnan, "Analysis of low cycle fatigue based on hysteresis energy," Fatigue \& Fracture of Engineering Materials \& Structures, vol. 3, no. 1, pp. 75-84, 1980.

[252] V. Kliman, "Fatigue life prediction for a material under programmable loading using the cyclic stress-strain properties," Materials Science and Engineering, vol. 68, no. 1, pp. 1-10, 1984.

[253] J. H. Huang, Y. Si, L. G. Zheng, and X. H. Dong, "A dislocation model of low-cycle fatigue damage and derivation of the CoffinManson equation," Materials Letters, vol. 15, no. 3, pp. 212-216, 1992.

[254] J. Polak, K. Obrtlik, and M. Hajek, "Cyclic plasticity in type 3161 austenitic stainless steel," Fatigue and Fracture of Engineering Materials and Structures, vol. 17, no. 7, pp. 773-782, 1994.

[255] J. S. Santner and M. E. Fine, "The hysteretic plastic work as a failure criterion in a Coffin-Manson type relation," Scripta Metallurgica, vol. 11, no. 2, pp. 159-162, 1977.

[256] S. S. Manson, "Fatigue: a complex subject-some simple approximations," Experimental Mechanics, vol. 5, pp. 193-226, 1965.

[257] S. S. Manson and G. R. Halford, Fatigue and Durability of Metals at High Temperatures, ASM International, West Conshohocken, $\mathrm{Pa}$, USA, 2009.

[258] U. Muralidharan and S. S. Manson, "A modified universal slopes equation for estimation of fatigue characteristics of metals," Journal of Engineering Materials and Technology, vol. 110, no. 1, pp. 55-58, 1988.

[259] M. R. Mitchell, Fatigue and Microstructures, American Society For Metals, 1979.

[260] K.-O. Lee, K.-H. Bae, and S.-B. Lee, “Comparison of prediction methods for low-cycle fatigue life of HIP superalloys at elevated temperatures for turbopump reliability," Materials Science and Engineering: A, vol. 519, no. 1-2, pp. 112-120, 2009.

[261] A. Bäumel and T. Seeger, Materials Data for Cyclic Loading, Elsevier, 1990.

[262] K.-O. Lee and S. B. Lee, "A comparison of methods for predicting the fatigue life of gray cast iron at elevated temperatures," Fatigue \& Fracture of Engineering Materials \& Structures, vol. 39, no. 4, pp. 439-452, 2016.

[263] G. Sines, "Failure of materials under combined repeated stresses with superimposed static stresses," Tech. Rep. NAAC-TN-3495, 1955. 
[264] H. Majors, D. D. Mills, and C. W. McGregor, "Fatigue under combined pulsating stresses," Journal of Applied Mechanics, vol. 16, pp. 269-276, 1949.

[265] D. Lefebvre, K. W. Neale, and F. Ellyin, "A criterion for lowcycle fatigue failure under biaxial states of stress," Journal of Engineering Materials and Technology, vol. 103, no. 1, pp. 1-6, 1981.

[266] Y. S. Garud, "A new approach to the evaluation of fatigue under multiaxial loadings," Journal of Engineering Materials and Technology, vol. 103, no. 2, pp. 118-125, 1981.

[267] K. Kanazawa, K. J. Miller, and M. W. Brown, "Low-cycle fatigue under out-of-phase loading conditions," Journal of Engineering Materials and Technology, vol. 99, no. 3, pp. 222-228, 1977.

[268] F. Ellyin, "A criterion for fatigue under multiaxial states of stress," Mechanics Research Communications, vol. 1, no. 4, pp. 219-224, 1974.

[269] G. Glinka, G. Shen, and A. Plumtree, "Multiaxial fatigue strain energy density parameter related to the critical fracture plane," Fatigue \& Fracture of Engineering Materials \& Structures, vol. 18, no. 1, pp. 37-46, 1995.

[270] E. Zalnezhad, A. A. D. Sarhan, and M. Hamdi, "Adhesion strength predicting of $\mathrm{Cr} / \mathrm{CrN}$ coated Al7075 using fuzzy logic system for fretting fatigue life enhancement," in Proceedings of the World Congress on Engineering and Computer Science, vol. 1, pp. 2-8, 2013.

[271] D. F. Socie, "Multiaxial fatigue damage models," Journal of Engineering Materials and Technology, vol. 109, no. 4, pp. 293298, 1987.

[272] C. C. Chu, F. A. Conle, and J. J. Bonnen, Multiaxial Stressstrain Modeling and Fatigue Life Prediction of SAE Axle Shafts, Advances in Multiaxial Fatigue, ASTM, 1993.

[273] T. Lagoda and E. Macha, "Generalization of energy-based multiaxial fatigue criteria to random loading," in Multiaxial Fatigue and Deformation: Testing and Prediction, ASTM, 2000.

[274] E. Zalnezhad and A. A. D. Sarhan, "Multilayer thin film CrN coating on aerospace AL7075-T6 alloy for surface integrity enhancement," International Journal of Advanced Manufacturing Technology, vol. 72, no. 9, pp. 1491-1502, 2014.

[275] T. Łagoda, "Energy models for fatigue life estimation under uniaxial random loading. Part I: the model elaboration," International Journal of Fatigue, vol. 23, no. 6, pp. 467-480, 2001.

[276] T. Łagoda, "Energy models for fatigue life estimation under uniaxial random loading. Part II: verification of the model," International Journal of Fatigue, vol. 23, no. 6, pp. 481-489, 2001.

[277] X. Su, "Toward an understanding of local variability of fatigue strength with microstructures," International Journal of Fatigue, vol. 30, no. 6, pp. 1007-1015, 2008.

[278] J. M. Boileau and J. E. Allison, "The effect of solidification time and heat treatment on the fatigue properties of a cast 319 aluminum alloy," Metallurgical and Materials Transactions A: Physical Metallurgy and Materials Science, vol. 34, no. 9, pp. 1807-1820, 2003.

[279] E. Zalnezhad, A. A. D. Sarhan, and M. Hamdi, "Optimizing the PVD TiN thin film coating's parameters on aerospace AL7075T6 alloy for higher coating hardness and adhesion with better tribological properties of the coating surface," The International Journal of Advanced Manufacturing Technology, vol. 64, no. 1, pp. 281-290, 2013.

[280] B. Skallerud, T. Iveland, and G. Härkegård, "Fatigue life assessment of aluminum alloys with casting defects," Engineering Fracture Mechanics, vol. 44, no. 6, pp. 857-874, 1993.
[281] M. J. Caton, J. W. Jones, J. E. Allison, J. C. J. Newman, and R. S. Piascik, Fatigue Crack Growth Thresholds, Endurance Limits and Design, ASTM, 2000.

[282] B. Bhattacharya and B. Ellingwood, "Continuum damage mechanics analysis of fatigue crack initiation," International Journal of Fatigue, vol. 20, no. 9, pp. 631-639, 1998.

[283] B. Bhattacharya, A damage mechanics based approach to structural deterioration and reliability [Ph.D. thesis], Johns Hopkins University, 1997.

[284] N. R. Hansen and H. L. Schreyer, "A thermodynamically consistent framework for theories of elastoplasticity coupled with damage," International Journal of Solids and Structures, vol. 31, no. 3, pp. 359-389, 1994.

[285] C. W. Gardiner, Handbook of Stochastic Methods for Physics, Chemistry and the Natural Sciences, Springer, New York, NY, USA, 1985.

[286] V. Dattoma, S. Giancane, R. Nobile, and F. W. Panella, "Fatigue life prediction under variable loading based on a new non-linear continuum damage mechanics model," International Journal of Fatigue, vol. 28, no. 2, pp. 89-95, 2006.

[287] S. Giancane, R. Nobile, F. W. Panella, and V. Dattoma, "Fatigue life prediction of notched components based on a new nonlinear Continuum Damage Mechanics model," Procedia Engineering, vol. 2, no. 1, pp. 1317-1325, 2010.

[288] L. M. Kachanov, Introduction to Continuum Damage Mechanics, Martinus Nijhoff, 1986.

[289] Y. N. Rabotnov, Creep Problems Under in Structural Members, John Wiley \& Sons, New York, NY, USA, 1969.

[290] J.-L. Chaboche, "Continuous damage mechanics-a tool to describe phenomena before crack initiation," Nuclear Engineering and Design, vol. 64, no. 2, pp. 233-247, 1981.

[291] J. Lamaitre and J. L. Chaboche, Mechanics of Solid Materials, Cambridge University Press, Cambridge, UK, 1990.

[292] O. Salomòn, S. Oller, and E. Oñate, "Fatigue analysis of materials and structures using continuum damage model," International Journal of Forming Processes, vol. 5, pp. 493-503, 2002.

[293] V. Velay, G. Bernhart, D. Delagnes, and L. Penazzi, "A continuum damage model applied to high-temperature fatigue lifetime prediction of a martensitic tool steel," Fatigue and Fracture of Engineering Materials and Structures, vol. 28, no. 11, pp. 1009-1023, 2005.

[294] R. Yuan, H. Li, H.-Z. Huang, S.-P. Zhu, and Y.-F. Li, "A new nonlinear continuum damage mechanics model for the fatigue life prediction under variable loading," Mechanika, vol. 19, no. 5, pp. 506-511, 2013.

[295] E. Santecchia, A. M. S. Hamouda, F. Musharavati, E. Zalnezhad, M. Cabibbo, and S. Spigarelli, "Wear resistance investigation of titanium nitride-based coatings," Ceramics International, vol. 9, pp. 10349-10379, 2015.

[296] J. J. Ping, M. Guang, S. Yi, and X. S. Bo, "A continuum damage mechanics model for creep fatigue life assessment of a steam turbine rotor," International Journal of Pressure Vessels and Piping, vol. 78, pp. 59-64, 2001.

[297] J. JianPing, M. Guang, S. Yi, and X. SongBo, "An effective continuum damage mechanics model for creep-fatigue life assessment of a steam turbine rotor," International Journal of Pressure Vessels and Piping, vol. 80, no. 6, pp. 389-396, 2003.

[298] R. Brighenti and A. Carpinteri, "A notch multiaxial-fatigue approach based on damage mechanics," International Journal of Fatigue, vol. 39, pp. 122-133, 2012. 
[299] M. Chaussumier, M. Shahzad, C. Mabru, R. Chieragatti, and F. Rezaï-Aria, "A fatigue multi-site cracks model using coalescence, short and long crack growth laws, for anodized aluminum alloys," Procedia Engineering, vol. 2, pp. 995-1004, 2010.

[300] M. Suraratchai, J. Limido, C. Mabru, and R. Chieragatti, "Modelling the influence of machined surface roughness on the fatigue life of aluminium alloy," International Journal of Fatigue, vol. 30, no. 12, pp. 2119-2126, 2008.

[301] M. Chaussumier, C. Mabru, M. Shahzad, R. Chieragatti, and F. Rezaï-Aria, "A predictive fatigue life model for anodized 7050 aluminium alloy," International Journal of Fatigue, vol. 48, pp. 205-213, 2013.

[302] R. E. Peterson, Stress Concentration Factors, John Wiley and Sons, 1974.

[303] E. Mohseni, E. Zalnezhad, A. A. D. Sarhan, and A. R. Bushroa, "A study on surface modification of Al7075-T6 alloy against fretting fatigue phenomenon," Advances in Materials Science and Engineering, vol. 2014, Article ID 474723, 17 pages, 2014.

[304] D. Arola and C. L. Williams, "Estimating the fatigue stress concentration factor of machined surfaces," International Journal of Fatigue, vol. 24, no. 9, pp. 923-930, 2002.

[305] S. K. Ås, B. Skallerud, B. W. Tveiten, and B. Holme, "Fatigue life prediction of machined components using finite element analysis of surface topography," International Journal of Fatigue, vol. 27, no. 10-12, pp. 1590-1596, 2005.

[306] D. M. Jafarlou, E. Zalnezhad, A. S. Hamouda, G. Faraji, N. A. B. Mardi, and M. A. H. Mohamed, "Evaluation of the mechanical properties of AA 6063 processed by severe plastic deformation," Metallurgical and Materials Transactions A, vol. 46, no. 5, pp. 2172-2184, 2015.

[307] M. H. El Haddad, N. E. Dowling, T. H. Topper, and K. N. Smith, "J-integral applications for short fatigue cracks at notches," International Journal of Fracture, vol. 16, no. 1, pp. 15-30, 1980.

[308] D. Taylor and O. M. Clancy, "The fatigue performance of machined surfaces," Fatigue \& Fracture of Engineering Materials \& Structures, vol. 14, pp. 329-336, 1991.

[309] S. Andrews and H. Sehitoglu, "A computer model for fatigue crack growth from rough surfaces," International Journal of Fatigue, vol. 22, no. 7, pp. 619-630, 2000.

[310] A. Staroselsky and B. N. Cassenti, "Creep, plasticity, and fatigue of single crystal superalloy," International Journal of Solids and Structures, vol. 48, no. 13, pp. 2060-2075, 2011.

[311] D. Rubeša, Lifetime Prediction and Constitutive Modeling for Creep-Fatigue Interaction, Gebrüder Borntraeger, 1996.

[312] J. S. Zhang, High Temperature Deformation and Fracture of Materials, Woodhead Publishing, 2010.

[313] Y.-C. Chiou and M.-C. Yip, "An energy-based damage parameter for the life prediction of aisi 304 stainless steel subjected to mean strain," Journal of the Chinese Institute of Engineers, vol. 29, no. 3, pp. 507-517, 2006.

[314] Z. Fan, X. Chen, L. Chen, and J. Jiang, "Fatigue-creep behavior of 1.25Cr0.5Mo steel at high temperature and its life prediction," International Journal of Fatigue, vol. 29, no. 6, pp. 1174-1183, 2007.

[315] W. M. Payten, D. W. Dean, and K. U. Snowden, "A strain energy density method for the prediction of creep-fatigue damage in high temperature components," Materials Science and Engineering: A, vol. 527, no. 7-8, pp. 1920-1925, 2010.

[316] S.-P. Zhu, H.-Z. Huang, H. Q. Li, R. Sun, and M. J. Zuo, "A new ductility exhaustion model for high temperature low cycle fatigue life prediction of turbine disk alloys," International Journal of Turbo and Jet Engines, vol. 28, no. 2, pp. 119-131, 2011.
[317] T. Gocmez, A. Awarke, and S. Pischinger, "A new low cycle fatigue criterion for isothermal and out-of-phase thermomechanical loading," International Journal of Fatigue, vol. 32, no. 4, pp. 769-779, 2010.

[318] S. Baradaran, E. Zalnezhad, W. J. Basirun et al., "Statistical optimization and fretting fatigue study of $\mathrm{Zr} / \mathrm{ZrO}_{2}$ nanotubular array coating on Ti-6Al-4V,', Surface and Coatings Technology, vol. 258, pp. 979-990, 2014.

[319] J. F. Saltsman and G. R. Halford, "An update on the total strain version of SRP," in Low Cycle Fatigue, ASTM, 1987.

[320] J. P. Pédron and A. Pineau, "The effect of microstructure and environment on the crack growth behaviour of Inconel 718 alloy at $650{ }^{\circ} \mathrm{C}$ under fatigue, creep and combined loading," Materials Science and Engineering, vol. 56, no. 2, pp. 143-156, 1982.

[321] L. F. Coffin, Fatigue, Annual Reviews, 1972.

[322] M. Bao and D. G. Shang, "New prediction method of fatigue life under random loading," Journal of Beijing Polytechnic University, vol. 27, pp. 434-436, 2001.

[323] T. Łagoda, E. Macha, and A. Niesłony, "Fatigue life calculation by means of the cycle counting and spectral methods under multiaxial random loading," Fatigue \& Fracture of Engineering Materials \& Structures, vol. 28, no. 4, pp. 409-420, 2005.

[324] D. G. Pavlou, "A phenomenological fatigue damage accumulation rule based on hardness increasing, for the 2024-T42 aluminum," Engineering Structures, vol. 24, no. 11, pp. 1363-1368, 2002.

[325] L. Y. Xie, "Definition of the effective stress for fatigue damage," Chinese Journal of Applied Mechanics, vol. 9, pp. 32-36, 1992.

[326] L. Wang, Z. Wang, and J. Zhao, "Life prediction by ferritepearlite microstructural simulation of short fatigue cracks at high temperature," International Journal of Fatigue, vol. 80, pp. 349-356, 2015.

[327] S. R. Yeratapally, M. G. Glavicic, M. Hardy, and M. D. Sangid, "Microstructure based fatigue life prediction framework for polycrystalline nickel-base superalloys with emphasis on the role played by twin boundaries in crack initiation," Acta Materialia, vol. 107, pp. 152-167, 2016.

[328] M. Naderi, M. Amiri, and M. M. Khonsari, "On the thermodynamic entropy of fatigue fracture," Proceedings of the Royal Society of London A: Mathematical, Physical and Engineering Sciences, vol. 466, no. 2114, pp. 423-438, 2010.

[329] E. Macha, T. Łagoda, A. Niesłony, and D. Kardas, "Fatigue life under variable-amplitude loading according to the cyclecounting and spectral methods," Materials Science, vol. 42, no. 3, pp. 416-425, 2006.

[330] J. Kim, J. Yi, J. Kim, G. Zi, and J. S. Kong, "Fatigue life prediction methodology using entropy index of stress interaction and crack severity index of effective stress," International Journal of Damage Mechanics, vol. 22, no. 3, pp. 375-392, 2013.

[331] L. D. Lutes and C. E. Larsen, "Improved spectral method for variable amplitude fatigue prediction," Journal of Structural Engineering, vol. 116, no. 4, pp. 1149-1164, 1990.

[332] G. Petrucci and B. Zuccarello, "Fatigue life prediction under wide band random loading," International Journal of Fatigue, vol. 27, pp. 1183-1195, 2004.

[333] C. Braccesi, F. Cianetti, G. Lori, and D. Pioli, "A frequency method for fatigue life estimation of mechanical components under bimodal random stress process," Structural Durability and Health Monitoring, vol. 1, no. 4, pp. 277-290, 2005.

[334] C. Braccesi, F. Cianetti, G. Lori, and D. Pioli, "The frequency domain approach in virtual fatigue estimation of non-linear 
systems: the problem of non-Gaussian states of stress," International Journal of Fatigue, vol. 31, no. 4, pp. 766-775, 2009.

[335] A. Carpinteri, A. Spagnoli, C. Ronchei, D. Scorza, and S. Vantadori, "Critical plane criterion for fatigue life calculation: time and frequency domain formulations," Procedia Engineering, vol. 101, pp. 518-523, 2015.

[336] C. Braccesi, F. Cianetti, and L. Tomassini, "An innovative modal approach for frequency domain stress recovery and fatigue damage evaluation," International Journal of Fatigue, vol. 91, part 2, pp. 382-396, 2016.

[337] A. Niesłony and M. Böhm, "Frequency-domain fatigue life estimation with mean stress correction," International Journal of Fatigue, vol. 91, pp. 373-381, 2016.

[338] K. Walat, "Selection of the best method for assessment of the fatigue life of aluminium alloys based on the root of the scatter mean-square value," Acta Mechanica et Automatica, vol. 6, no. 1, pp. 86-88, 2012.

[339] C. Braccesi, F. Cianetti, G. Lori, and D. Pioli, "Evaluation of mechanical component fatigue behavior under random loads: indirect frequency domain method," International Journal of Fatigue, vol. 61, pp. 141-150, 2014.

[340] C. Braccesi, F. Cianetti, and L. Tomassini, "Random fatigue. A new frequency domain criterion for the damage evaluation of mechanical components,' International Journal of Fatigue, vol. 70, pp. 417-427, 2015.

[341] C. E. Larsen and T. Irvine, "A review of spectral methods for variable amplitude fatigue prediction and new results," Procedia Engineering, vol. 101, pp. 243-250, 2015.

[342] C. Braccesi, F. Cianetti, and L. Tomassini, "Validation of a new method for frequency domain dynamic simulation and damage evaluation of mechanical components modelled with modal approach," Procedia Engineering, vol. 101, pp. 493-500, 2015. 

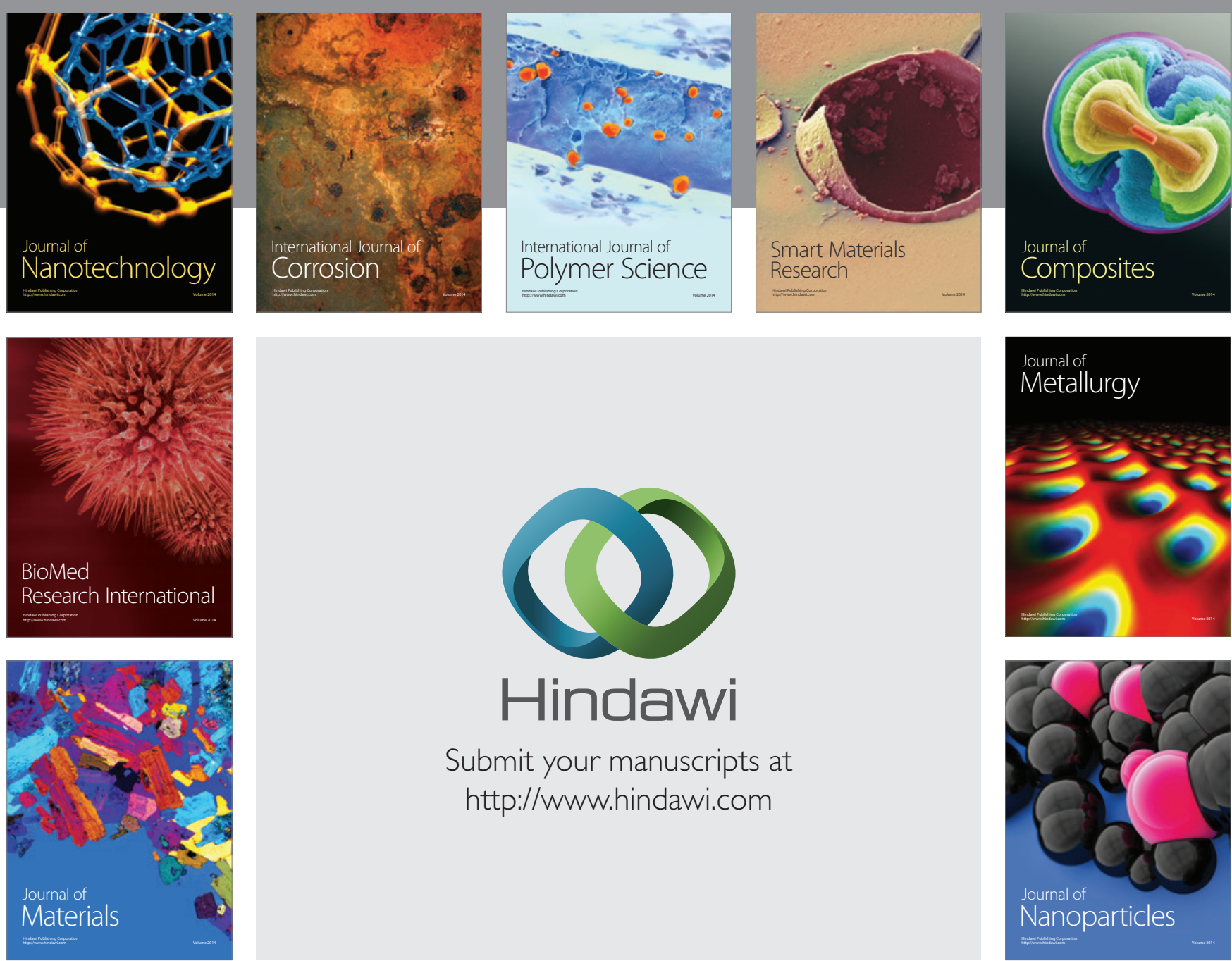

\section{Hindawi}

Submit your manuscripts at

http://www.hindawi.com

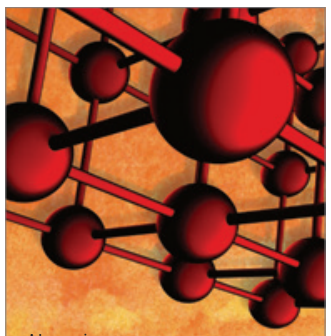

Materials Science and Engineering
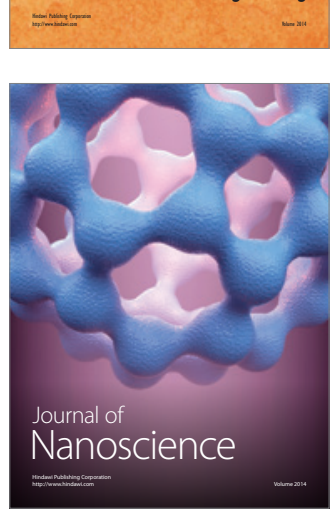
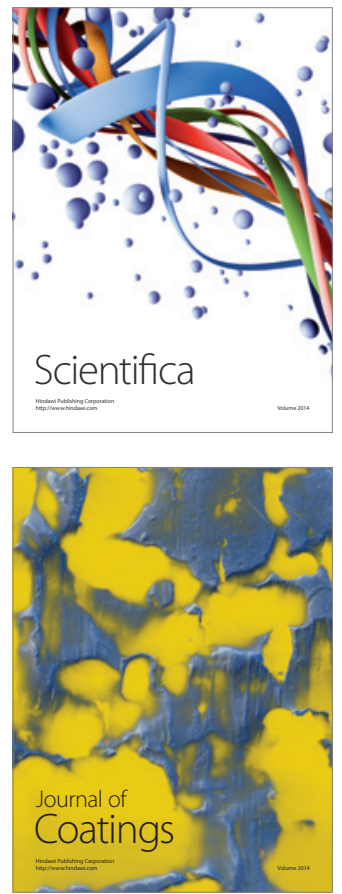
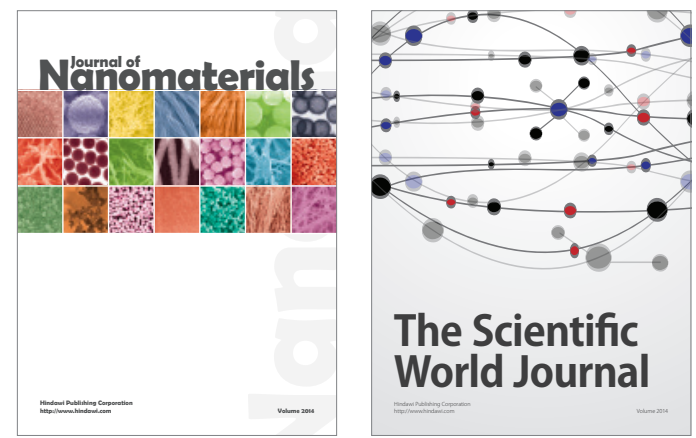

The Scientific World Journal
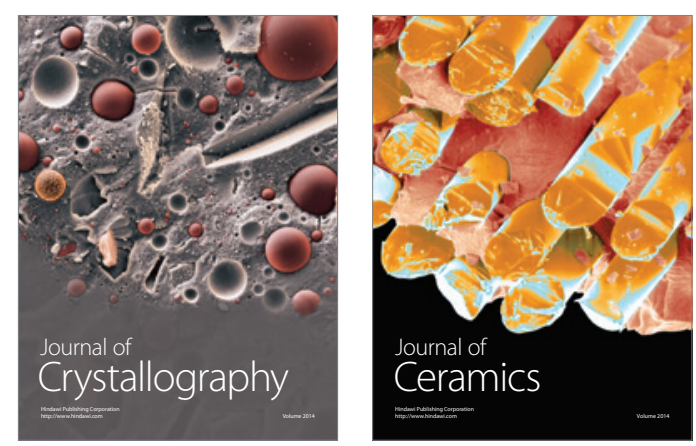
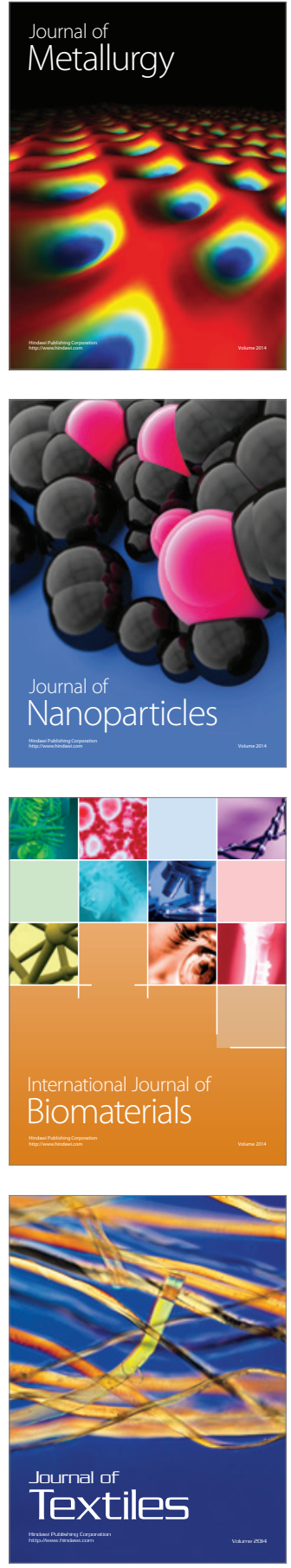